\title{
Innate immunity promotes sleep through epidermal antimicrobial peptides
}

Marina P. Sinner ${ }^{1,2,3 \bullet}$, Florentin Masurat ${ }^{3 \bullet}$, Jonathan J. Ewbank ${ }^{4}$, Nathalie Pujol ${ }^{4}$, Henrik Bringmann ${ }^{1,2,3 *}$

1 BIOTEC, Technical University Dresden, Germany

2 University of Marburg, Germany

3 Max Planck Institute for Biophysical Chemistry, Göttingen, Germany

4 Aix Marseille Université, Inserm, CNRS, CIML, Turing Centre for Living Systems, Marseille, France

*Lead contact: henrik.bringmann@biologie.uni-marburg.de

๑These authors contributed equally to this work. 
Graphical Abstract

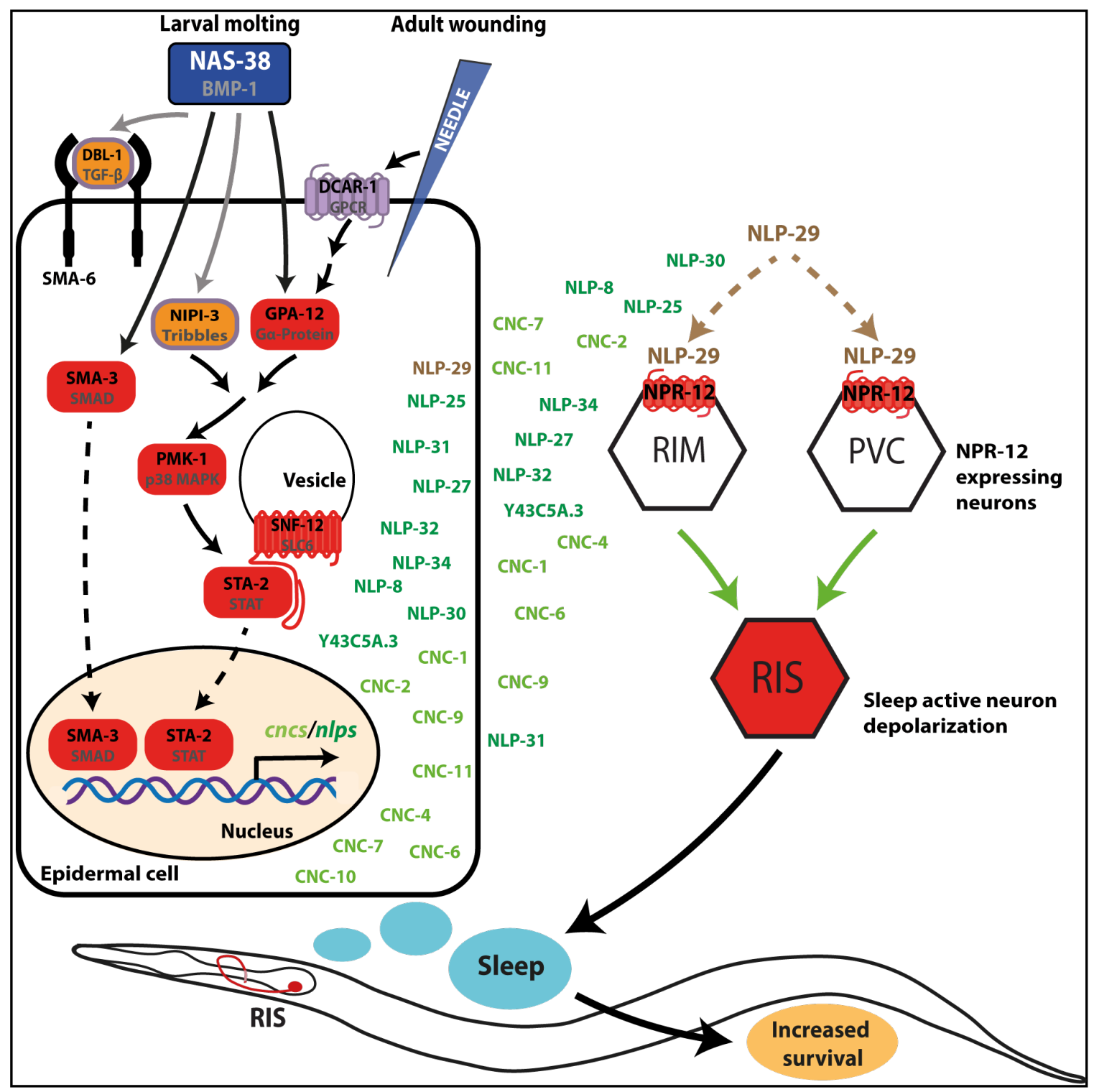




\section{Summary}

Wounding and infection trigger a protective innate immune response that includes the production of antimicrobial peptides in the affected tissue as well as increased sleep. Little is known, however, how peripheral wounds or innate immunity signal to the nervous system to increase sleep. We found that during C. elegans larval molting, an epidermal tolloid/BMP-1-like protein called NAS-38 promotes sleep. NAS-38 is negatively regulated by its thrombospondin domain and acts through its astacin protease domain to activate p38 MAP/PMK-1 kinase and TGF- $\beta$-SMAD/SMA-3-dependent innate immune pathways in the epidermis that cause STAT/STA-2 and SLC6 (solute carrier)/SNF-12-dependent expression of antimicrobial peptide (AMP) genes. We show that more than a dozen epidermal AMPs act as somnogens, signaling across tissues to promote sleep through the sleep-active RIS neuron. In the adult, epidermal injury activates innate immunity and turns up AMP production to trigger sleep, a process that overlaps with EGFR signaling that is known to promote sleep following cellular stress. We show for one AMP, NLP-29, that it acts through the neuropeptide receptor NPR-12 in locomotion-controlling neurons that are presynaptic to RIS and that depolarize this neuron to induce sleep. Sleep in turn increases the chance of surviving injury. Thus, we found a novel mechanism by which peripheral wounds signal to the nervous system to increase protective sleep. Such a cross-tissue somnogen signaling function of AMPs might also boost sleep in other animals including humans. 


\section{Introduction}

Following infection or wounding, the innate immune system is activated to destroy invading pathogens. In mammals, innate immunity includes an acute phase response, during which non-REM sleep, a restorative type of sleep, is increased $[1,2]$. The amount of non-REM sleep correlates positively with the capacity of experimental animals to recover after infection [3]. More generally, proper sleep is needed to mount a normal immune response $[4,5]$. Conversely, sleep loss is associated with impaired wound healing in animal models [6-8]. Among the effects of severe sleep deprivation are skin lesions and impaired adaptive as well as innate immunity, potentially leading to death by sepsis [9].

As neural circuits control sleep, any impact of the immune system on sleep would be expected to be via the nervous system. From worms to humans, sleep is induced by sleepactive sleep-inducing neurons that express inhibitory neuropeptides and GABA [10-12]. In mammals, pro-inflammatory cytokines and prostaglandins appear to alter the excitability of neurons and promote sleep $[1,2,4,5,13]$. Peripheral tissues of the body also modulate sleep [5, 14-16]. However, little is known about the mechanisms by which the immune system and peripheral tissues signal to the brain to control the activity of sleep-active neurons.

Antimicrobial peptides (AMPs) are produced as a part of the innate immune response and can directly attack pathogens [17]. In Drosophila, an AMP called nemuri has been proposed to serve two functions. In peripheral tissues, its expression is increased upon infection and it may act directly in antimicrobial defense. In the brain, it is expressed and functions in neurons upstream of the dorsal fan-shaped body, a region known to control sleep. Following sleep deprivation, nemuri expression is increased in the head and promotes sleep [18]. In addition to sleep-controlling mechanisms in the brain, a long-range signaling mechanism across tissues must exist that signals from infected peripheral tissues to the brain. This mechanism, however, remains unidentified and it is unknown whether peripheral AMPs play a role in this process. 
In C. elegans, sleep has been studied in the developing larva as well as in the adult [15, 19]. Sleep in C. elegans is characterized as extended periods of behavioral inactivity and reduced responsiveness. At the end of each larval cycle, sleep occurs during a developmental phase called lethargus, a period of time that coincides with synthesis of a new cuticle [20,21]. Sleep during lethargus is induced by the sleep-active GABAergic and peptidergic neuron RIS [22-24].

C. elegans lacks adaptive immunity, but it possesses an innate immune system [25-27]. Immune pathways in C. elegans can be triggered by pathogen infection and sterile injury of the epidermis [28-31]. Surveillance systems detect the presence of molecular patterns associated with physical damage, pathogens, and the cellular perturbation that they cause. Once such patterns are detected, intracellular signaling mechanisms are set off to induce the production of effectors that attack the pathogen or promote cell protection [32]. One of the key innate immune signaling pathways in the worm consists of a conserved p38 MAP kinase phosphorylation cascade [26, 28, 33, 34]. The p38 MAP kinase pathway can be triggered by several mechanisms, one of which involves activation of a damage-associated molecular pattern receptor (DAMP receptor) called DCAR-1 that then signals through a $\mathrm{G}$ alpha protein called GPA-12 to activate a protein kinase C delta (TPA-1) [29, 35]. An alternative activator during infection is the Tribbles homolog NIPI-3 [28]. PMK-1 triggers activation of the STAT transcription factor STA-2, which, together with a SLC6 solute carrier called SNF-12, leads to AMP expression [28, 35, 36]. Another important conserved pathway in $C$. elegans activated by pathogens is the TGF- $\beta$-SMAD pathway [37]. The ligand TGF- $\beta /$ DBL-1 activates its receptor during fungal infection, which signals through the SMAD protein SMA-3 to boost AMP production in synergy with STA-2 [36, 38]. Here, we delineate a novel cross-tissue signaling mechanism by which innate immune pathways employ AMPs to signal damage to the nervous system to increase sleep.

\section{Results}

\section{A dominant mutation in the tolloid/BMP-1-like nas-38 gene increases sleep}


To identify novel genetic pathways controlling sleep in C. elegans, we conducted a largescale reverse genetic screen for mutants that display increased larval sleep. Out of about 4,500 mutants, 155 displayed increased behavioral quiescence (Table S1). A deletion in the nas-38 gene, (ok3407), was associated with an unusually high fraction of immobile larvae. We hence quantified developmental time, lethargus length, and quiescence behavior as a proxy for sleep in nas-38(ok3407). nas-38(ok3407) L1 larvae developed with slightly reduced speed until the onset of lethargus. The lethargus phase, however, was specifically and dramatically extended more than twofold in nas-38(ok3407) (Figure 1A-D). Also, the fraction of time spent in sleep was doubled resulting in a total sleep time increase of about four-fold compared with the wild type (Figure 1E). To test whether the sleep phenotype was recessive or dominant, we tested heterozygous nas-38(ok3407) worms, which showed a modest increase in both lethargus length and total time in movement quiescence, suggesting that nas-38(ok3407) is semi-dominant (Figure S1A-B).

To assess the loss-of-function phenotype of nas-38, we analyzed sleep in a deletion mutant, nas-38(tm2655) that likely presents a molecular null. We measured movement quiescence, the time from hatching to lethargus onset, and lethargus length. nas-38(tm2655) showed slightly reduced movement quiescence (Figure 1E), a modest reduction of time from hatching until lethargus (reduction by 5.6\%, Figure S1C), and the lethargus length was specifically shortened (Figure S1C, Figure 1D-E). Thus, nas-38(tm2655) showed the opposite phenotype to nas-38(ok3407). Together these results indicate that nas-38(ok3407) is a strong gain-of-function allele that dramatically increases lethargus length and sleeping behavior.

NAS-38 belongs to the conserved family of astacin zinc metalloproteases, which play diverse roles in extracellular matrix processing as well as in extracellular signaling pathways [39]. The structure of NAS-38 is similar to that of the bone morphogenic protein (BMP-1), but has a reduced number of CUB and EGF domains and has an additional TSP1 domain (Figure 1F) [39]. For a structure-function analysis, we constructed different precise gene deletions of nas-38 (Figures 1F, S1D). A clean deletion of the C-terminus from the same position where nas-38(ok3407) is truncated, nas-38(syb293), completely 
recapitulated the quiescence phenotypes of nas-38(ok3407), confirming that they are indeed caused by the removal of the C-terminus (Figures S1A-B). As the C-terminus includes a thrombospondin (TSP1) domain, we tested in a specific in-frame deletion of the TSP1 domain, nas-38(knu568), whether the absence of this domain causes the quiescence phenotypes. While lethargus duration was increased only slightly, movement quiescence was strongly increased in nas-38(knu568), showing that increased sleep is caused mostly by TSP1 absence, suggesting that the TSP1 domain normally represses NAS-38 activity in the wild type (Figure 1D-E). Measuring movement quiescence and lethargus length in heterozygous nas-38(knu568) worms suggested that this allele is dominant (Figure S1AB). To test whether nas-38(ok3407) acts through its astacin domain, we engineered an inframe deletion of this domain in the gain-of-function allele (nas-38(knu579ok3407)). Astacin domain deletion completely suppressed the increased movement quiescence and lethargus length phenotype of nas-38(ok3407), suggesting that protease activity is essential for NAS-38 function (Figure 1D-E). Together, these results suggest an inhibitory function for the TSP1 domain in NAS-38 and indicate that the astacin protease domain is required for NAS-38 functions. The lethargus and sleep duration phenotypes were influenced to different extents by the nas-38 mutations. Absence of the complete C-terminus including the TSP1 domain caused a prominent increase in both lethargus duration and sleep amount, whereas selective deletion of the TSP1 domain strongly increased only sleep amount.

\section{NAS-38 is expressed in the epidermis and increases sleep through the RIS neuron}

Sleep during lethargus is induced by the sleep-active RIS neuron [22, 40]. To test whether sleep in nas-38(ok3407) depends on RIS, we inactivated RIS genetically in nas-38(ok3407) by expression of egl-1 [41] and a molecular null mutation in aptf-1 [22, 40]. In the nas38(ok3407) mutant background, RIS impairment reduced the lethargus length by about one quarter (Figure 1G). aptf-1 (gk794) suppressed movement quiescence in nas-38(ok3407) almost completely, and RIS(-) by more than two thirds (Figure 1H). These results indicate that nas-38(ok3407) increases sleep mostly by acting through RIS. 
We generated a transcriptional (promoter) fusion with a destabilized fluorescent reporter (d1GFP) [42] and followed nas-38 expression across larval development using fluorescence microscopy time-lapse imaging. nas-38 was expressed in the epidermis excluding seam cells and also in the excretory canal cell, duct cell, pore cell and excretory gland cell but not in the RIS neuron (Figure 1I). Expression was first detectable in the embryo. During lethargus, expression strongly increased and decreased again after the end of each lethargus period (Figure 1J). Thus, consistent with high-throughput expression data [43, 44], nas-38 is expressed in epithelial cells in an oscillating expression pattern with an increase during lethargus.

\section{nas-38 promotes expression of immune response genes}

To find out how nas-38 controls quiescence behavior and to identify the downstream effectors, we analyzed the transcriptomes of nas-38 mutants during lethargus. We manually isolated wild-type, nas-38(tm2655) loss-of-function, and nas-38(ok3407) gain-of-function worms during L4 lethargus. The worms were then subjected to RNAseq and differentially expressed genes were extracted. The transcriptome of nas-38(tm2655) showed only moderate changes compared with the wild type. By contrast, the transcriptome of nas38(ok3407) was massively changed, with hundreds of genes changing their expression compared to the wild type (Figure 2A). The strength of the gene expression changes in the mutants thus matched the strength of the behavioral phenotypes for the two nas-38 mutations.

Tissue enrichment analysis showed that the differentially expressed genes in nas38(ok3407) were most strongly associated with secretion, which is consistent with the expression pattern of nas-38 in excretory tissues (Figure S2). Gene enrichment analysis showed that the upregulated genes were most strongly associated with formation of the cuticle and with innate immunity responses (Figure 2B). The innate immune response in the epidermis involves the production of AMPs such as a specific subset of NLPs (neuropeptide like proteins) and CNCs (caenacins) [28, 45]. AMPs of the $n l p$ and $c n c$ gene 
families increased their expression up to several hundred-fold in the nas-38(ok3407) transcriptome (Figure 2C).

Epidermal AMPs are synthesized during infection but also after sterile wounding and in specific cuticular collagen mutants [28, 46]. Some epidermal AMPs are also expressed specifically during molting [44, 47-49]. We therefore tested whether the set of $n l p$ and $c n c$ peptide genes that were overexpressed in nas-38(ok3407) was more similar to those AMPs that have been reported to be induced by the immune response after fungal infection [50] or to peptide genes that have been shown to be rhythmically expressed during lethargus [51]. Out of 17 significantly upregulated AMPs in the nas-38(ok3407) transcriptome, 15 corresponded to AMPs upregulated after infection and only 3 to significant hits during lethargus (Figure 2C). This suggested that nas-38(ok3407) generates an AMP response that is most similar to the innate immune response.

To validate the transcriptome changes in nas-38(ok3407), we looked at reporter gene expression of NLP-29, a representative of the $n l p$ AMP cluster [28, 52]. Expression from the $n l p-29$ promoter was strongly increased in the epidermis in nas-38(ok3407) (Figure 2D-E). Expression of the AMP-regulating transcription factor STA-2 increased 4.3-fold in the nas-38(ok3407) transcriptome. Upon activation, STA-2 is presumed to translocate into the nucleus [36]. We thus imaged a translational reporter fusion of STA-2 in epidermal cells during lethargus and quantified the fraction of STA-2 that was localized to the nucleus. The reporter was indeed expressed at 1.5-fold higher levels in the cytoplasm in the nas-38(ok3407) background. In addition, nas-38(ok3407) led to an increase of the nuclear fraction of STA-2 (Figure 2F-G). In summary, nas-38(ok3407) led to massive transcriptional alterations, activation of the innate immune response, and increased transcription of AMPs that are expressed in the epidermis.

\section{NAS-38 promotes sleep through innate immune response genes}


To test whether nas-38 acts through innate immune genes, we performed epistasis experiments. We focused on two conserved immune pathways, the first acting through a p38 MAP kinase and the second acting through DBL-1/TGF- $\beta$-SMAD signaling (Figure $3 \mathrm{~A})$. We crossed mutants of key genes of these pathways into our gain-of-function mutants nas-38(knu568) and nas-38(ok3407) to test for suppression of quiescence behavior and lethargus length, respectively. Mutation of the most upstream components of the p38 MAP kinase pathway dcar-1 (damage receptor) and nipi-3 (tribbles) did not suppress increased quiescence of nas-38(ok3407) worms (Figure S3A-B). Mutations of gpa-12 (G alpha protein), pmk-1 (p38 MAP kinase), snf-12 (solute carrier), and sta-2 (STAT) that are further downstream in the pathway could, however, suppress increased quiescence (Figure 3B-C, S3A-D). For the TGF- $\beta$-SMAD pathway, mutation of $d b l-1$ (TGF- $\beta$ ligand) could not significantly suppress increased quiescence. A mutation in sma-3 (SMAD), however, partially suppressed nas-38(knu568)-increased movement quiescence (Figure 3B). The same genes that suppressed increased movement quiescence in nas-38(knu568) also suppressed prolonged lethargus duration in nas-38(ok3407) (Figures 3C, and S3D). We next tested whether the p38 MAP kinase and the TGF- $\beta$-SMAD pathway act in parallel. As the simultaneous knockout of sta-2 and $s m a-3$ was inviable, we tested a double mutant of sma-3 and pmk-1, which reduced nas-38(ok3407) lethargus duration more than each mutation individually, suggesting that the two immune pathways act in parallel to promote lethargus length (Figure S3B).

\section{NAS-38 is required in the epidermis to increase AMP expression}

To study the effects of $n a s-38$ on AMP expression, we quantified $n l p-29 p:: G F P$ expression across lethargus [28]. nlp-29 expression oscillated with the developmental cycle and increased during lethargus (Figure 3D). Expression of $n l p-29$ was strongly increased in nas-38(ok3407), moderately increased in nas-38(knu568), and decreased by about half in

nas-38(tm2655) (Figure 3D). Thus, the level of $n l p-29$ expression correlated with the amount of sleep. We next assayed the suppression of overexpression of $n l p-29$ in nas38 (ok3407) by the same components of the innate immune response pathway that we had 
tested for quiescence suppression before. The expression of $n l p-29$ was suppressed by genes of the p38 MAP kinase pathway and, to a lesser degree, by genes of the DBL-1/TGF$\beta$-SMAD signaling pathway (Figures 3E-G, S4A-G). Thus, nas-38 acts through innate immune response genes to increase expression in the epidermis of AMP genes including $n l p-29$. Overall, high expression of $n l p-29$ in mutants correlated with increased sleep behavior, and suppression of $n l p-29$ expression was correlated with suppression of increased sleep behavior (Figure $3 \mathrm{H}$ ).

nas-38 is expressed prominently in the epidermis and there promotes AMP expression through STA-2 [36]. To confirm this directly, we knocked down nas-38(ok3407) with RNAi specifically in the epidermis [53]. This suppressed the increased $n l p-29$ expression phenotype to a similar extent as $s t a-2$, supporting the idea that nas-38 acts in skin tissue (Figures 3I, S4H).

\section{nas-38 acts through AMPs to increase sleep}

To test whether nas-38(ok3407) increases sleep through AMPs, we crossed knockout alleles of an individual AMP, nlp-29, and another neuropeptide-like gene that was overexpressed in nas-38(ok3407), nlp-8, into the nas-38(ok3407) mutant and analyzed quiescence behavior. Neither deletion could suppress increased quiescence in nas38(ok3407) (Figures S5A-B).

As the members of the NLP and CNC families have very similar sequences $[45,54]$, they may act redundantly. To test this hypothesis, we created a strain that simultaneously deleted 19 nlp and $c n c$ genes. The multi nlp/cnc deletion strain did not have obvious sleep or lethargus defects on its own. However, nlp/cnc deletion partially suppressed increased movement quiescence and lethargus duration of nas-38(ok3407), particularly in the first part of the lethargus phase (Figure 4). To corroborate the suppression phenotype, we knocked down all the significantly upregulated $n l p$ and $c n c$ genes simultaneously by RNAi. The multi nlp/cnc knockdown partially suppressed quiescence in nas-38(ok3407) (Figure 
S5C-D). Thus, $n l p$ and $c n c$ genes increase sleep and lethargus duration of nas-38(ok3407). The partial nas-38(ok3407) suppression phenotype suggests that additional genes may be involved in sleep induction.

\section{Wounding-induced sleep involves NLPs and CNCs to activate RIS}

Many types of cellular stress, including heat and wounding, increase sleep. Heat stressinduced sleep requires the ALA and the RIS neuron, but so far only an involvement of ALA has been demonstrated in wounding-induced sleep $[15,16,55,56]$. We thus tested whether skin wounding causes sleep through RIS depolarization [28, 30]. Needle and laser wounding increased motion quiescence with a concomitant calcium increase in RIS (Figures 5A-D, S6A-C). Wounding-induced movement quiescence was strongly reduced in ALA-deficient ceh-14(-) animals [16] and virtually abolished in the RIS-deficient aptf$1(g k 794)$ mutant [22]. These data indicate that wounding triggers RIS activation to promote movement quiescence, a process that involves the ALA neuron (Figure 5D).

To test whether wounding-induced sleep requires nas-38 or the innate immune response, we measured movement quiescence following mechanical wounding in nas-38, sta-2, and AMP mutants. nas-38 mutations did not affect movement quiescence in adults (Figure S6D). sta-2(ok1860) and the multi $n l p / c n c$ knockout reduced movement quiescence after wounding by half (Figure 5E). These data indicate that nas-38(ok3407) during molting, and injury of the adult epidermis, are separate triggers that both activate innate immunity to cause sleep. Thus, we identified innate immunity as a novel molecular pathway for promoting sleep in C. elegans.

We next tested whether innate immunity is required for heat stress-induced sleep. sta-2() did not reduce heat shock-induced movement quiescence. No effect was observed either in mutants for $n p r-12$ (Figure S6E) that lack the cognate receptor for NLP-29 [57], suggesting that the signaling pathways triggering heat stress-induced sleep and woundinginduced sleep are at least partially distinct. Neuronal EGFR is required for stress-induced 
sleep $[16,56]$. To test whether neuronal EGFR is also required for sleep following epidermal wounding, we knocked down the EGFR receptor gene let-23 specifically in neurons [56], which strongly reduced movement quiescence following injury. The combined loss of sta-2 and neuronal let-23 did not further reduce movement quiescence (Figures 5E, S6F). This indicates that both wounding- and heat stress-induced sleep require neuronal EGFR signaling.

\section{NLPs and CNCs can induce sleep through the RIS neuron}

To test whether each of the $n l p$ and $c n c$ genes that were upregulated in nas-38(ok3407) can promote sleep, we conditionally and broadly overexpressed each gene individually by using a heat-shock promoter. To induce expression, adult worms were heat shocked and scored manually afterwards for feeding and movement quiescence. For all $17 \mathrm{nlp}$ and $c n c$ genes tested, overexpression led to an induction of quiescence behavior after about 0.5-2.5 $\mathrm{h}$ that was not observed in control heat-shocked worms (Figure 6A and S7A-Q). To test whether NLPs and CNCs act through RIS, we scored quiescence induction by overexpression of $n l p$ and $c n c$ genes in aptf-1(-), which efficiently suppressed most of the overexpression-induced quiescence (Figure 6A and S7A-Q). Thus, $n l p$ and $c n c$ genes function as somnogens that act through RIS to increase sleep.

\section{NLP-29 acts through the neuropeptide receptor NPR-12}

NLP-29 has been shown to bind to and activate the NPR-12 neuropeptide receptor to control dendrite degeneration [57]. We hence wanted to test whether NLP-29-induced sleep requires NPR-12. We crossed npr-12(-) into the NLP-29 overexpression strain, induced NLP-29 by a heat shock in adult worms, and tested for suppression of movement quiescence. In $n p r-12(-)$ animals, the amount of movement quiescence was reduced by half in the $0.5-3.25 \mathrm{~h}$ following the induction of NLP-29 overexpression (Figure 6B). Thus, NLP-29 increases sleep though NPR-12. The neuropeptide receptor is not expressed in 
RIS, but in several other neurons including the PVC and RIM interneurons [57, 58], which control locomotion and are key activators of RIS [59]. We hence tested whether NPR-12 acts in RIM and PVC by expressing $n p r-12(+)$ in RIM and PVC from the $n m r-1$ promoter in an $n p r-12(-)$ background, and tested for rescue of the movement quiescence phenotype following NLP-29 overexpression. $n p r-12(+)$ increased movement quiescence in both the wild-type and npr-12(-) background and partially rescued the npr-12(-) phenotype (Figure 6C). This suggests that NLP-29 signals sleep to the nervous system through the NPR-12 neuropeptide receptor in neuronal circuits that control RIS.

\section{Genetic sleep deprivation decreases the chance to survive injury}

The increase of sleep by wounding suggests that sleep induction by innate immunity might increase survive after injury. To test this idea, we wounded animals and tested whether individuals were still alive $24 \mathrm{~h}$ and $48 \mathrm{~h}$ after the insult. Wild-type animals showed a moderate percentage of dead individuals upon wounding. By contrast, aptf-1(-), in which sleep was impaired, had an almost tripled risk of dying following the injury (Figure 7AB). In addition, knockdown of $n l p / c n c$ genes also reduced the chance to survive the injury. These data indicate that $n l p / c n c$ genes and sleep provide an advantage for surviving injury, thus demonstrating a biological significance for innate immunity-induced sleep (Figure 7C).

\section{Discussion}

\section{Epidermal AMPs activate a sleep-inducing neural circuit}

Tolloids are metalloproteases that are involved in collagen processing required for formation of the extracellular matrix $[39,60]$. The role of tolloid-related factors in matrix processing appears to be conserved in C. elegans [61-64]. Tolloid-related proteins also play a second role, in developmental processes. Tolloid in Drosophila is well known as a 
developmental factor that acts by cleaving decapentaplegic, a TGF- $\beta$ homolog, which in turn leads to transcriptional changes. Similarly, BMP1 in mammals also cleaves TGF- $\beta$ [39]. Here we show that NAS-38 activation triggers an innate immune response during larval molting. NAS-38, similar to Tolloid/BMP-1, acts through TGF- $\beta$ /DBL-1 pathway component SMA-3, demonstrating that the canonical signaling components of the tolloid pathway have been conserved in C. elegans. NAS-38 signals through a heterotrimeric G protein subunit onto the p38 MAP kinase pathway. Both pathways lead to the activation of STA-2 in the epidermis and AMP expression [36]. These innate immune pathways are normally triggered by injury and infection. Thus, NAS-38 activation might act by causing an injury, perhaps through its protease function in collagen remodeling during molting. While we did not observe any obvious molting defects in nas-38 mutants, they might have cuticle defects. In addition, NAS-38 could act directly through activation of TGF- $\beta$ signaling. The lack of a quiescence phenotype for the AMP knockout strain during lethargus suggests that there are redundant pathways that promote sleep during molting, and one of these pathways appears to be an immune response promoted by NAS-38.

In adult animals, innate immunity is triggered by wounding and infection [28, 36, 38]. Wounding of human epidermal keratinocytes activates the STAT proteins STAT3 and STAT5B and leads to the production of AMPs such as $\beta$-defensins and pro-inflammatory cytokines (IL-6 and IL-8) [65]. Pro-inflammatory cytokines such as IL-1 $\beta$, TNF- $\alpha$, and IL6 induce sleep and are involved in the increased sleepiness caused by infection $[1,2,66]$. AMPs can bind to and interfere with microbial membranes, and also act as modulators of the immune system, but whether and how peripheral AMPs control sleep was unclear. The AMP encoded by nemuri has been shown to be expressed and act in the brain to promote sleep, perhaps by acting like a sleep-promoting neurotransmitter [18].

We show for C. elegans that wounding increases sleep through activation of epidermal innate immunity and AMPs and we hypothesize that they may also play this role following infection. Thus, we describe an additional, novel role for a large group of AMPs. We show that AMPs can act as long-range somnogen messenger molecules that are expressed in peripheral tissues, such as the epidermis, and promote sleep in the brain. AMPs might also 
act as long-range somnogens that signal across tissues in other organisms. We show that many AMPs act redundantly to promote sleep, and potential additional sleep-promoting AMPs exist in C. elegans. The high number of AMPs that we found to be able to promote sleep is striking and may reflect the biological importance of innate immunity-induced sleep. Speculatively, it could increase the robustness of the sleep response, and circumvent potential subversion of immune signaling by pathogens. AMPs are thought to be secreted basolaterally from the epidermis to activate the NPR-12 neuropeptide receptor in the PVD sensory neuron, to modulate aging pathways in this neuron [57], and we propose that basolateral secretion of AMPs might also underlie increased sleep following injury. The NPR-12 receptor is expressed and functions in circuits that include neurons that are known to control depolarization of RIS, but not in RIS itself, thus suggesting a model in which RIS is depolarized by NPR-12-expressing circuits, which are controlled by NLP-29. Whether other AMPs also activate NPR-12 and whether additional receptors exist that respond to specific AMPs are interesting questions for future studies.

Seminal work showed that cellular stress increases sleep through EGF signaling $[15,16$, 55]. Our work suggests that EGF-induced sleep and AMP-induced sleep might function in overlapping pathways following injury. The molecular mechanisms of the interaction of innate immune pathways with EGFR signaling in sleep control merit investigation.

In summary, we have discovered a cross-tissue signaling mechanism that connects peripheral skin wounding to sleep induction via AMPs that signal sleep from the site of injury to the brain, causing sleep neuron activation and thus sleep (Figure 7C). Our data suggest that increasing sleep following injury provides a selective advantage as it almost triples the chance of surviving. AMPs might also serve as a long-range signaling cue across tissues to promote sleep following wounding to increase the chance of recuperation in other organisms including mammals.

\section{Acknowledgments}


We thank Ines Lewandrowski, Sinem Öztas, Juliane Haase, Jerome Belougne and Shizue Omi for help with some experiments. We thank Dong Yan, National BioResource Project Japan, and the Caenorhabditis Genetics Center supported by the National Institutes of Health Office of Research Infrastructure Programs (P40 OD010440) for strains. The CRISPR strains were generated by SunyBiotech and Knudra. We thank Hirofumi Toda for discussing the role of nemuri. This work was supported by the Max Planck Society (Max Planck Research Group "Sleep and Waking"), by an European Research Council Starting Grant (ID: 637860, SLEEPCONTROL), the French National Research Agency (ANR-16CE15-0001-01), by the « Investissements d'Avenir » French Government program (ANR16-CONV-0001) and from Excellence Initiative of Aix-Marseille University - A*MIDEX and institutional grants from CNRS, Aix Marseille University, and INSERM to the CIML.

\section{Author Contributions}

M.S. and F.M. designed, performed and analyzed experiments to quantify developmental time, movement quiescence and lethargus duration, time-resolved $n l p-29 p: \because G F P$ and RIS GCaMP intensities, differential gene expression in nas-38 mutants, STA-2::mKate2 localization and survival rates after wounding, took the images of nas-38p::d1GFP, nlp29p::GFP, and STA-2::mKate2 expressing worms, created most of the reagents and strains, created the figures, drafted the respective methods parts, and edited the manuscript. J.E. and N.P. provided advice on wounding and immune experiments, conceived, carried out and analyzed the COPAS Biosorter experiments, and edited the manuscript.

H.B. conceived the overall outline of the project, acquired funding for the project, carried out the reverse genetic screen together with I.L., designed experiments, supervised the work, and wrote the manuscript.

All authors approved the final version of this manuscript.

\section{Declaration of Interest}

The authors declare no competing interests.

\section{Supplementary Table 1: $C$. elegans strains screened for quiescence phenotypes.}

Supplementary Table 2: Differentially expressed genes in nas-38 mutants compared to wild type. 
Figure 1. nas-38 increases sleep during lethargus through the RIS neuron.

(A-B) Image subtraction data of one representative wild-type and one nas-38(ok3407) worm.

(C) Lethargus is specifically prolonged in nas-38(ok3407). The time from hatching until the beginning of lethargus is increased by $11.6 \%$ (10.9 $\mathrm{h}$ in wild type and $12.1 \mathrm{~h}$ in nas$38(o k 3407)$ ). Lethargus length is prolonged by $214.9 \%$ (1.7 $\mathrm{h}$ in wild type, $3.6 \mathrm{~h}$ in $n a s-$ 38(ok3407)), mean values \pm SEM, two sample t-test.

(D) The loss-of-function allele nas-38(tm2655) shortened lethargus duration by $15.2 \%$. nas-38(knu568) increased lethargus duration only slightly by $23.4 \%$, nas-38(ok3407) prolonged lethargus by $115.7 \%$, two sample t-test.

(E) nas-38(knu568) and nas-38(ok3407) increased movement quiescence by $219.0 \%$ and $355.2 \%$, respectively, compared to the wild type. This effect was completely suppressed by a deletion of the astacin domain $(77.3 \%$ mean reduction of movement quiescence compared to nas-38(ok3407), no significant difference in nas-38(knu579ok3407) compared to the wild type), two-sample t-test.

(F) Domain structures of different nas-38 alleles. Frameshift mutation deletes the thrombospondin-1 domain and the C-terminus in ok3407. nas-38(tm2655) lacks most of the functional protein, including the astacin domain. nas-38(knu568) specifically lacks the thrombospondin-1 domain. nas-38(knu579ok3407) deletes the astacin domain in ok3407.

(G) RIS(-) decreased lethargus duration of nas-38(ok3407) by $25.3 \%$. Data were compared against the same wild-type and nas-38(ok3407) data as in (D), two-sample ttest.

(H) In the wild type and in nas-38(ok3407), loss of RIS and aptf-1(gk794) reduced movement quiescence during lethargus. In nas-38(ok3407), aptf-1(gk794) reduced movement quiescence by $90.3 \%$ and RIS(-) by $69.1 \%$, two-sample t-test. The wild-type and nas-38(ok3407) data are the same as in (E). The effects of RIS(-) were variable, perhaps due to silencing of the transgene.

(I) Left panel: L2 larva expressing nas-38::d1GFP during lethargus inside a microchamber. GFP is mainly expressed in the epidermis except the seam cells. EC 
indicates the excretory cell. Right panel: immobilized L4 larva during lethargus. Shown is the merged image of the brightfield and GFP channel. Pore cell (PC), duct cell (DC) and the excretory gland cells (EG).

(J) nas-38 expression oscillates with lethargus. During lethargus it increased by $20.0 \%$, and dropped afterwards, paired Wilcoxon rank test.

See also Figure S1. 
Figure 2. NAS-38 promotes innate immunity gene expression.

(A) Heatmap of the statistically significant transcriptional changes in nas-38(ok3407) and nas-38(tm2655) compared to the wild type.

(B) Gene set enrichment analysis of differentially expressed genes revealed similarities with immunity and defense responses as well as with lethargus.

(C) Comparison of differential expression of nlps and cncs in nas-38(ok3407), infected worms and wild-type larvae during lethargus by negative binomial testing.

(D) Expression of $n l p-29 p:: G F P$ is strongly increased in nas-38(ok3407) L4 larvae.

Expression in the wild type is visible only under conditions that cause saturation of the signal in nas-38(ok3407).

(E) Fluorescence quantification reveals an upregulation of $n l p-29 p:$ GFP by an average of $966.6 \%$ in a mixed population in the nas-38(ok3407) mutant.

(F) A STA-2::mKate2 fusion protein expressed under the endogenous sta-2 promoter revealed an increase in expression as well as nuclear localization of STA-2.

(G) Cytoplasmic and nuclear STA-2::mKate2 quantification. Data were normalized to wild-type levels. In nas-38(ok3407), cytoplasmic STA-2 increased 1.5-fold and nuclear STA-2 increased 1.7-fold, two-sample t-test.

See also Figure S2 and Supplementary Table 2. 
Figure 3. NAS-38 increases movement quiescence and lethargus length through TGFB/SMAD and p38 MAP-Kinase innate immune response pathways.

(A) Cartoon summarizing the pathways involved in mediating increased sleep caused by nas-38. Proteins corresponding to mutants that suppressed quiescence in nas-38 gain-offunction mutants are marked in red.

(B) $s m a-3(e 491)$ reduced movement quiescence in nas-38(knu568) by $41.2 \%$, pmk$1(\mathrm{~km} 25)$ by $43.7 \%$, sta-2(ok1860) by $55.5 \%$ and $s n f-12(\mathrm{tm} 692)$ by $77.2 \%$. Shown are the same wild-type and nas-38(knu568) data as in Figure 1E, two sample t-test.

(C) pmk-1 (km25) decreased lethargus length in nas-38(ok3407) by $17.5 \%$, sta-2(ok1860) by $29.6 \%$, and $s n f-12(t m 692)$ by $49.8 \%$, two-sample t-test. Data were compared against the same wild-type and nas-38(ok3407) measurements as in Figure 1D.

(D) - (G) $n l p-29 p: \because G F P$ intensity levels $8 \mathrm{~h}$ before and after lethargus onset. The same wild-type and nas-38(ok3407) data are repeatedly shown in every panel.

(D) nas-38(ok3407) increased nlp-29p::GFP expression by $120.5 \%$, nas-38(knu568) increased $n l p-29 p:: G F P$ expression by $45.1 \%$ and the $n a s-38(\operatorname{tm} 2655)$ allele decreased nlp-29p::GFP expression by $69.5 \% 4 \mathrm{~h}$ after lethargus onset.

(E) - (G) Suppression of nas-38(ok3407) induced nlp-29p::GFP expression in mutants

of innate immune pathways. gpa-12(pk322) suppressed fluorescence intensity by $71.3 \%$, sta-2(ok1860) by $97.5 \%$ and snf-12(tm692) by $81.0 \%$. Shown are mean values \pm SEM.

(H) Suppression of $n l p-29 p:: G F P$ expression in nas-38(ok3407) positively correlates with suppression of lethargus increase and movement quiescence increase in nas-38 gainof-function alleles.

(I) Systemic and epidermis-specific RNAi of nas-38 RNAi and sta-2 suppress nas38(ok3407)-induced $n l p-29 p:: G F P$ expression.

See also Figures S3-S4.

\section{Figure 4. NAS-38 increases sleep through AMPs}

(A) The $n l p$ and $c n c$ multi gene knockout suppressed increased movement quiescence in nas-38(ok3407) by $27.6 \%$. 
(B) The nlp and $c n c$ multi gene knockout suppressed prolonged lethargus duration in nas38(ok3407) by $17.0 \%$. nas-38(ok3407) data from Figures 1D and E are shown, twosample t-test.

(C-D) Fraction of worms in movement quiescence during lethargus for the $n l p$ and $c n c$ multiple gene knockout plotted as a function of time.

\section{Figure 5. Wounding induces sleep via the RIS and ALA neurons as well as the innate immune response, AMPs, and EGFR signaling.}

(A) An individual trace of a representative wild-type worm without wounding lacks RIS depolarization transients and sleep.

(B) Data of an example wild-type worm after sterile needle wounding. RIS activation transients are visible and coincide with movement quiescence.

(C) Average velocity and RIS calcium activity after needle wounding aligned to sleep onset. RIS calcium activity $\left(\mathrm{F} / \mathrm{F}_{0}\right)$ increased by an average of $27.8 \%$ during sleep, paired Wilcoxon rank test.

(D) Worms without wounding showed almost no movement quiescence. Needlewounded wild-type individuals were quiescent $15.4 \%$ of the time. aptf-1 (gk794) reduced movement quiescence by $95.2 \%$. ceh-14(ch3) suppressed movement quiescence after wounding by $60.5 \%$.

(E) sta-2(ok1860) suppressed movement quiescence after wounding by $59.0 \%$ and the $n l p / c n c$ multi gene knockout by $47.2 \%$. The pan-neuronal let-23 KO suppressed movement quiescence by $79.2 \%$. A double mutant of sta-2(ok1860) and the panneuronal let-23 $\mathrm{KO}$ resulted in a mean movement quiescence suppression of 79.3 $\%$, two-sample t-test. Data are compared against the same wild-type data as in Figure 5D.

See also Figure S6. 
Figure 6. Many AMPs can induce sleep in the adult worm via RIS, and NLP-29induced sleep requires the NPR-12 neuropeptide receptor, which acts in neurons upstream of RIS

(A) Effect of $n l p$ and $c n c$ gene overexpression on behavioral quiescence in the wild type and in aptf-1(gk794). Movement and feeding quiescence were scored 30 - 150 min after the heat shock. aptf-1(gk794) reduced endogenous quiescence after heat shock by $89.5 \%$. aptf-1 (gk794) also reduced AMP overexpression (OE)-induced behavioral quiescence significantly in almost all conditions $(92.7 \%$ in cnc-6 OE, $83.8 \%$ in $n l p-8 \mathrm{OE}, 88.9 \%$ in $n l p-25 \mathrm{OE}, 92.2 \%$ in $n l p-32 \mathrm{OE}, 90.0 \%$ in $n l p-34 \mathrm{OE}, 82.3 \%$ in $n l p-30 \mathrm{OE}, 62.3 \%$ in Y43C5A.3 OE, $81.9 \%$ in cnc- 11 OE, $87.7 \%$ in $n l p-27$ OE, $93.3 \%$ in $n l p-29 \mathrm{OE}, 95.7 \%$ in $c n c-1 \mathrm{OE}, 100.0 \%$ in $c n c-2 \mathrm{OE}, 84.1 \%$ in $c n c-9 \mathrm{OE}, 93.9 \%$ in $c n c-7 \mathrm{OE}, 83.4 \%$ in $n l p-31 \mathrm{OE}$, and $87.5 \%$ in $c n c-4 \mathrm{OE})$, Fisher's exact test.

(B) Knockout of the neuropeptide receptor gene $n p r-12$ suppressed $n l p$-29 overexpression-induced movement quiescence by $55.5 \%$.

(C) Rescue of $n p r-12(-)$ from the $n m r-1$ promoter. Following NLP-29 overexpression, nmr-1p::npr-12 partially restored movement quiescence in the npr-12(-) background. nmr-1p::npr-12 worms spent an average of $12.9 \%$ of the time in movement quiescence. In the presence of $n m r-1 p:: n p r-12$, npr-12(-) suppressed NLP-29 induced movement quiescence by only $20.7 \%$, two sample t-test.

See also Figure S7. 
Figure 7. Sleep increases survival after wounding.

(A) - (B) Needle wounding caused moderate mortality in young adults (12\% after $24 \mathrm{~h}$ and $14 \% 48 \mathrm{~h}$ after wounding). Sleepless aptf-1(gk794) mutant worms and worms lacking 19 AMP genes were significantly more likely to die from the injury than the wild type (34\% of aptf-1 (gk794) were dead after $24 \mathrm{~h}$ and $42 \%$ after $48 \mathrm{~h} .32 \%$ of the multi nlp/cnc KO animals were dead after 48 h, Fisher's exact test).

(C) Cartoon model for how NAS-38 and sterile wounding induce sleep via an innate immune response pathway. Activation of innate immunity pathways by NAS-38 in the epidermis leads to an increase of AMP expression and secretion. AMPs then activate receptors including NPR-12 in neuronal circuits that control RIS activity. Activation of RIS ultimately leads to sleep induction. Proteins corresponding to mutants that suppressed the induction of sleep in nas-38gf are marked in red. Proteins corresponding to mutants that suppressed only nas-38(ok3407)-induced NLP-29 expression are shown in orange.

\section{Material and Methods}

\section{KEY RESOURCES TABLE}

\begin{tabular}{|c|c|c|}
\hline REAGENT or RESOURCE & SOURCE & IDENTIFIER \\
\hline \multicolumn{3}{|l|}{ C. elegans strains } \\
\hline wild type & CGC & $\begin{array}{l}\text { N2 (1A, 1C-E, 1G- } \\
\text { H, 2A-C, 3B-C, 4A- } \\
\text { C, 5D-E, 6A-B, 7A- } \\
\text { B, S1A-C, S2, S3A- } \\
\text { B, S5A-D, S6D-F) }\end{array}$ \\
\hline $\begin{array}{l}\text { let-23(zh131[FRT::let- } \\
\text { 23::FRT::GFP::LoxP::FLAG::let-23] II. }\end{array}$ & [60] & AH5059 (S6F) \\
\hline $\begin{array}{l}\text { let-23(zh131[FRT::let- } \\
\text { 23::FRT::GFP::LoxP::FLAG::let-23] II; bqSi506 } \\
\text { [rgef-1p::FLP D5 + unc-119(+)] IV. }\end{array}$ & [60] & AH5529 (5E, S6F) \\
\hline sma-3(e491) III. & CGC & CB491 (3B-C) \\
\hline nas-38(knu568) X. & $\begin{array}{l}\text { Knudra } \\
\text { Transgenics for this } \\
\text { project }\end{array}$ & $\begin{array}{l}\text { COP1622 (1D-E, } \\
\text { 3B, 3H, S1A-B, } \\
\text { S3D) }\end{array}$ \\
\hline nas-38(knu579ok3407) X. & $\begin{array}{l}\text { Knudra } \\
\text { Transgenics for this } \\
\text { project }\end{array}$ & COP1635 (1D-E) \\
\hline
\end{tabular}




\begin{tabular}{|c|c|c|}
\hline nas-38(ok3407) X. & This project & $\begin{array}{l}\text { HBR1010 (1B-E, } \\
\text { 1G-H, 2A-C, 3C, } \\
\text { 3H, 4A-B, 4D, } \\
\text { S1A-B, S2, S3A-C, } \\
\text { S5A-D, S6D) }\end{array}$ \\
\hline frIs7[nlp-29p::GFP+coel-12p::dsRed] IV. & This project & $\begin{array}{l}\text { HBR1089 (2D-E, } \\
\text { 3D-G, S4A-G) }\end{array}$ \\
\hline $\begin{array}{l}\text { frIs7[nlp-29p::GFP, coel-12p::DsRed] IV, nas- } \\
\text { 38(ok3407) X. }\end{array}$ & This project & $\begin{array}{l}\text { HBR1090 (2D-E, } \\
\text { 3D-I, S4A-G) }\end{array}$ \\
\hline $\begin{array}{l}\text { unc-119(ed3) III; goels257[nas-38p::d1 mgfp::nas- } \\
\text { 38-3'-UTR, unc-119(+)]. }\end{array}$ & This project & HBR1110 (1I-J) \\
\hline nas-38(tm2655) X. & $\begin{array}{l}\text { National } \\
\text { BioResource } \\
\text { Project, Japan }\end{array}$ & $\begin{array}{l}\text { HBR1114 (1D-E, } \\
\text { 2A, S1C, S6D) }\end{array}$ \\
\hline $\begin{array}{l}\text { frIs7[nlp-29p::GFP + coel-12p::DsRed] IV; nas-38 } \\
\text { (tm2655) X. }\end{array}$ & This project & HBR1117 (3D) \\
\hline nlp-29 (tm1931) V; nas-38(ok3407) X. & This project & HBR1272 (S5A-B) \\
\hline $\begin{array}{l}\text { goeIs304[flp-11p::SL1-GCaMP3.35-SL2::mKate2- } \\
\text { unc-54-3'UTR, unc-119(+)]. }\end{array}$ & [49] & $\begin{array}{l}\text { HBR1361 (5A-C, } \\
\text { S6A-B) }\end{array}$ \\
\hline sta-2(ok1860) V; nas-38(ok3407) X. & This project & $\begin{array}{l}\text { HBR1541 (3C, } \\
\text { S3C) }\end{array}$ \\
\hline $\begin{array}{l}\text { aptf-1(gk794) II; goeIs326[hsp-16.2p::nlp- } \\
\text { 29::SL2-mkate2-unc-54-3'UTR, unc-119(+)]. }\end{array}$ & This project & $\begin{array}{l}\text { HBR1547 (6A, } \\
\text { S7M) }\end{array}$ \\
\hline $\begin{array}{l}\text { goeIs326[hsp-16.2p::nlp-29::SL2-mkate2-unc-54- } \\
\text { 3'UTR, unc-119(+)]. }\end{array}$ & This project & $\begin{array}{l}\text { HBR1549 (6A-B, } \\
\text { S7M) }\end{array}$ \\
\hline nlp-29(tm1931) V. & This project & HBR1556 (s5A-B) \\
\hline $\begin{array}{l}\text { goels384 [flp-11p::egl-1::SL2-mkate2-flp-11-3'utr, } \\
\text { unc-119(+)]. }\end{array}$ & {$[49]$} & HBR1777 (1D-E, \\
\hline $\begin{array}{l}\text { frIs7[nlp-29p::GFP, coel-12p::DsRed] IV; gpa- } \\
\text { 12(pk322), nas-38(ok3407) X. }\end{array}$ & This project & $\begin{array}{l}\text { HBR1877 (3E, 3H, } \\
\text { S3A-B, S4G) }\end{array}$ \\
\hline pmk-1(km25) IV; nas-38(ok3407) X. & This project & $\begin{array}{l}\text { HBR1878 (3C, } \\
\text { S3C) }\end{array}$ \\
\hline $\begin{array}{l}\text { sma-3(e491) III; frIs7[nlp-29p::GFP, coel- } \\
\text { 12p::dsRed] IV; nas-38(ok3407) X. }\end{array}$ & This project & $\begin{array}{l}\text { HBR1884 (3C, 3H, } \\
\text { S3C, S4B, S4G) }\end{array}$ \\
\hline $\begin{array}{l}\text { aptf-1(gk794) II; goels388[hsp-16.2p::cnc-1::SL2- } \\
\text { mkate2-unc-54-3'utr, unc-119(+)]. }\end{array}$ & This project & $\begin{array}{l}\text { HBR1892 (6A, } \\
\text { S7A) }\end{array}$ \\
\hline $\begin{array}{l}\text { aptf-1(gk794) II; goels397[hsp-16.2p::cnc- } \\
\text { 10::SL2-mkate2-unc-54-3'utr, unc-119(+)]. }\end{array}$ & This project & $\begin{array}{l}\text { HBR1893 (6A, } \\
\text { S7G) }\end{array}$ \\
\hline $\begin{array}{l}\text { aptf-1(gk794) II; goels406[hsp-16.2p::nlp- } \\
\text { 31::SL2-mkate2-unc-54-3'utr, unc-119(+)]. }\end{array}$ & This project & $\begin{array}{l}\text { HBR1894 (6A, } \\
\text { S70) }\end{array}$ \\
\hline $\begin{array}{l}\text { aptf-1(gk794) II; goels407[hsp-16.2p::cnc-2::SL2- } \\
\text { mkate2-unc-54-3'utr, unc-119(+)]. }\end{array}$ & This project & $\begin{array}{l}\text { HBR1895 (6A, } \\
\text { S7B) }\end{array}$ \\
\hline $\begin{array}{l}\text { goels388[hsp-16.2p::cnc-1::SL2-mkate2-unc-54- } \\
\text { 3'utr, unc-119(+)]. }\end{array}$ & This project & $\begin{array}{l}\text { HBR1896 (6A, } \\
\text { S7A) }\end{array}$ \\
\hline
\end{tabular}




\begin{tabular}{|c|c|c|}
\hline $\begin{array}{l}\text { goeIs397[hsp-16.2p::cnc-10::SL2-mkate2-unc-54- } \\
\text { 3'utr, unc-119(+)]. }\end{array}$ & This project & $\begin{array}{l}\text { HBR1897 (6A, } \\
\text { S7G) }\end{array}$ \\
\hline $\begin{array}{l}\text { goeEx651[hsp-16.2p::nlp-34::SL2-mkate2-unc-54- } \\
\text { 3'utr, unc-119(+)]. }\end{array}$ & This project & $\begin{array}{l}\text { HBR1898 (6A, } \\
\text { S7Q) }\end{array}$ \\
\hline $\begin{array}{l}\text { goels406[hsp-16.2p::nlp-31::SL2-mkate2-unc-54- } \\
\text { 3'utr, unc-119(+)]. }\end{array}$ & This project & $\begin{array}{l}\text { HBR1899 (6A, } \\
\text { S70) }\end{array}$ \\
\hline $\begin{array}{l}\text { goeIs408[hsp-16.2p::nlp-27::SL2-mkate2-unc-54- } \\
\text { 3'utr, unc-119(+)]. }\end{array}$ & This project & $\begin{array}{l}\text { HBR1900 (6A, } \\
\text { S7L) }\end{array}$ \\
\hline $\begin{array}{l}\text { goels407[hsp-16.2p::cnc-2::SL2-mkate2-unc-54- } \\
\text { 3'utr, unc-119(+)]. }\end{array}$ & This project & $\begin{array}{l}\text { HBR1901 (6A, } \\
\text { S7B) }\end{array}$ \\
\hline $\begin{array}{l}\text { goeIs409[hsp-16.2p::nlp-32::SL2-mkate2-unc-54- } \\
\text { 3'utr, unc-119(+)]. }\end{array}$ & This project & $\begin{array}{l}\text { HBR1902 (6A, } \\
\text { S7P) }\end{array}$ \\
\hline $\begin{array}{l}\text { goeEx667[hsp-16.2p::nlp-8::SL2-mkate2-unc-54- } \\
\text { 3'utr, unc-119(+)]. }\end{array}$ & This project & $\begin{array}{l}\text { HBR1903 (6A, } \\
\text { S7J) }\end{array}$ \\
\hline $\begin{array}{l}\text { aptf-1(gk794) II; goeEx667[hsp-16.2p::nlp-8::SL2- } \\
\text { mkate2-unc-54-3'utr, unc-119(+)]. }\end{array}$ & This project & $\begin{array}{l}\text { HBR1904 (6A, } \\
\text { S7J) }\end{array}$ \\
\hline $\begin{array}{l}\text { goeEx672[hsp-16.2p::cnc-11::SL2-mkate2-unc-54- } \\
\text { 3'utr, unc-119(+)]. }\end{array}$ & This project & $\begin{array}{l}\text { HBR1905 (6A, } \\
\text { S7H) }\end{array}$ \\
\hline $\begin{array}{l}\text { aptf-1(gk794) II; goeEx672[hsp-16.2p::cnc- } \\
\text { 11::SL2-mkate2-unc-54-3'utr, unc-119(+)]. }\end{array}$ & This project & $\begin{array}{l}\text { HBR1906 (6A, } \\
\text { S7H) }\end{array}$ \\
\hline $\begin{array}{l}\text { goels410[hsp-16.2p::cnc-6::SL2-mkate2-unc-54- } \\
\text { 3'utr, unc-119(+)]. }\end{array}$ & This project & $\begin{array}{l}\text { HBR1907 (6A, } \\
\text { S7D) }\end{array}$ \\
\hline $\begin{array}{l}\text { aptf-1(gk794) II; goeIs410[hsp-16.2p::cnc-6::SL2- } \\
\text { mkate2-unc-54-3'utr, unc-119(+)]. }\end{array}$ & This project & $\begin{array}{l}\text { HBR1908 (6A, } \\
\text { S7D) }\end{array}$ \\
\hline $\begin{array}{l}\text { goeEx676[hsp-16.2p::nlp-30::SL2-mkate2-unc-54- } \\
\text { 3'utr, unc-119(+)]. }\end{array}$ & This project & $\begin{array}{l}\text { HBR1909 (6A, } \\
\text { S7N) }\end{array}$ \\
\hline $\begin{array}{l}\text { aptf-1(gk794) II; goeEx676[hsp-16.2p::nlp- } \\
\text { 30::SL2-mkate2-unc-54-3'utr, unc-119(+)]. }\end{array}$ & This project & $\begin{array}{l}\text { HBR1910 (6A, } \\
\text { S7N) }\end{array}$ \\
\hline $\begin{array}{l}\text { goels411[hsp-16.2p::cnc-4::SL2-mkate2-unc-54- } \\
\text { 3'utr, unc-119(+)]. }\end{array}$ & This project & $\begin{array}{l}\text { HBR1911 (6A, } \\
\text { S7C) }\end{array}$ \\
\hline $\begin{array}{l}\text { goels412[hsp-16.2p::cnc-7::SL2-mkate2-unc-54- } \\
\text { 3'utr, unc-119(+)]. }\end{array}$ & This project & $\begin{array}{l}\text { HBR1912 (6A, } \\
\text { S7E) }\end{array}$ \\
\hline $\begin{array}{l}\text { aptf-1(gk794) II; goels412[hsp-16.2p::cnc-7::SL2- } \\
\text { mkate2-unc-54-3'utr, unc-119(+)]. }\end{array}$ & This project & $\begin{array}{l}\text { HBR1913 (6A, } \\
\text { S7E) }\end{array}$ \\
\hline $\begin{array}{l}\text { goels413[hsp-16.2p::cnc-9::SL2-mkate2-unc-54- } \\
\text { 3'utr, unc-119(+)]. }\end{array}$ & This project & $\begin{array}{l}\text { HBR1914 (6A, } \\
\text { S7F) }\end{array}$ \\
\hline $\begin{array}{l}\text { aptf-1(gk794) II; goels413[hsp-16.2p::cnc-9::SL2- } \\
\text { mkate2-unc-54-3'utr, unc-119(+)]. }\end{array}$ & This project & $\begin{array}{l}\text { HBR1915 (6A, } \\
\text { S7F) }\end{array}$ \\
\hline $\begin{array}{l}\text { frIs7[nlp-29p::GFP, coel-12p::DsRed] IV; dbl- } \\
\text { 1(nk3) V; nas-38(ok3407) X. }\end{array}$ & This project & $\begin{array}{l}\text { HBR1923 (3C, 3H, } \\
\text { S3C, S4A, S4G) }\end{array}$ \\
\hline $\begin{array}{l}\text { frSi11[pNP152(sta-2p::STA-2::mkate2); unc- } \\
119(+ \text { ) ttTi5605] II; nas-38(ok3407) X. }\end{array}$ & This project & HBR1925 (2F-G) \\
\hline $\begin{array}{l}\text { frIs7[nlp-29p::GFP, coel-12p::DsRed] IV; sta- } \\
\text { 2(ok1860) V; nas-38(ok3407) X. }\end{array}$ & This project & $\begin{array}{l}\text { HBR1928 (3F, 3H, } \\
\text { S4G) }\end{array}$ \\
\hline
\end{tabular}




\begin{tabular}{|c|c|c|}
\hline $\begin{array}{l}\text { aptf-1(gk794) II; goeIs408[hsp-16.2p::nlp- } \\
\text { 27::SL2-mkate2-unc-54-3'utr, unc-119(+)]. }\end{array}$ & This project & $\begin{array}{l}\text { HBR1957 (6A, } \\
\text { S7L) }\end{array}$ \\
\hline $\begin{array}{l}\text { aptf-1(gk794) II; goeIs409[hsp-16.2p::nlp- } \\
\text { 32::SL2-mkate2-unc-54-3'utr, unc-119(+)]. }\end{array}$ & This project & $\begin{array}{l}\text { HBR1958 (6A, } \\
\text { S7P) }\end{array}$ \\
\hline $\begin{array}{l}\text { goeEx651[hsp-16.2p::nlp-34::SL2-mkate2-unc-54- } \\
\text { 3'utr, unc-119(+)]; aptf-1(gk794) II. }\end{array}$ & This project & $\begin{array}{l}\text { HBR1959 (6A, } \\
\text { S7Q) }\end{array}$ \\
\hline $\begin{array}{l}\text { aptf-1(gk794) II; goeIs411[hsp-16.2p::cnc-4::SL2- } \\
\text { mkate2-unc-54-3'utr, unc-119(+)]. }\end{array}$ & This project & $\begin{array}{l}\text { HBR1960 (6A, } \\
\text { S7C) }\end{array}$ \\
\hline $\begin{array}{l}\text { goeIs431[hsp-16.2p::nlp-25::SL2-mkate2-unc-54- } \\
\text { 3'utr, unc-119(+)]. }\end{array}$ & This project & $\begin{array}{l}\text { HBR1961 (6A, } \\
\text { S7K) }\end{array}$ \\
\hline $\begin{array}{l}\text { aptf-1(gk794) II; goeIs431[hsp-16.2p::nlp- } \\
\text { 25::SL2-mkate2-unc-54-3'utr, unc-119(+)]. }\end{array}$ & This project & $\begin{array}{l}\text { HBR1962 (6A, } \\
\text { S7K) }\end{array}$ \\
\hline $\begin{array}{l}\text { goeEx657[hsp-16.2p::Y43C5A.3::SL2-mkate2-unc- } \\
\text { 54-3'utr, unc-119(+)]. }\end{array}$ & This project & $\begin{array}{l}\text { HBR1963 (6A, } \\
\text { S7I) }\end{array}$ \\
\hline $\begin{array}{l}\text { aptf-1(gk794) II; goeEx657[hsp- } \\
\text { 16.2p::Y43C5A.3::SL2-mkate2-unc-54-3'utr, unc- } \\
\text { 119(+)]. }\end{array}$ & This project & $\begin{array}{l}\text { HBR1964 (6A, } \\
\text { S7I) }\end{array}$ \\
\hline $\begin{array}{l}\text { sma-3(e491) III; pmk-1(km25), frIs7[nlp- } \\
\text { 29p::GFP, coel-12p::DsRed] IV. }\end{array}$ & This project & $\begin{array}{l}\text { HBR2010 (S3A-B, } \\
\text { S4F-G) }\end{array}$ \\
\hline $\begin{array}{l}\text { sma-3(e491) III; pmk-1(km25), frIs7[nlp- } \\
\text { 29p::GFP, coel-12p::DsRed] IV; nas-38(ok3407) X. }\end{array}$ & This project & $\begin{array}{l}\text { HBR2014 (3H, } \\
\text { S3A-B, S4F-G) }\end{array}$ \\
\hline $\begin{array}{l}\text { nas-38(ok3407) X; goeIs384[flp-11p::egl-1::SL2- } \\
\text { mkate2-flp-11-3'utr; unc-119(+)]. }\end{array}$ & This project & HBR2072 (1G-H) \\
\hline sta-2(ok1860) V; nas-38(knu568) X. & This project & $\begin{array}{l}\text { HBR2090 (3B, 3H, } \\
\text { S3D) }\end{array}$ \\
\hline $\begin{array}{l}\text { frIs7[nlp-29p::GFP, coel-12p::DsRed] IV; dbl- } \\
\text { 1(nk3)V. }\end{array}$ & This project & HBR2127 \\
\hline $\begin{array}{l}\text { frIs7[nlp-29p::GFP, coel-12p::DsRed] IV; nas- } \\
\text { 38(knu568) X. }\end{array}$ & This project & HBR2145 (3D) \\
\hline $\begin{array}{l}\text { sma-3(e491) III; frIs7[nlp-29p::GFP, coel- } \\
\text { 12p::DsRed] IV. }\end{array}$ & This project & HBR2146 \\
\hline $\begin{array}{l}\text { sma-3(e491) III; frIs7[nlp-29p::GFP, coel- } \\
\text { 12p::DsRed]IV; nas-38(knu568) X. }\end{array}$ & This project & $\begin{array}{l}\text { HBR2185 (3B, } \\
\text { 3H1, S3D) }\end{array}$ \\
\hline $\begin{array}{l}\text { frIs7[nlp-29p::GFP, coel-12p::DsRed] IV; dbl- } \\
\text { 1(nk3) V; nas-38(knu568)X. }\end{array}$ & This project & $\begin{array}{l}\text { HBR2186 }(3 \mathrm{~B}, 3 \mathrm{H}, \\
\text { S3D) }\end{array}$ \\
\hline $\begin{array}{l}\text { frIs7[nlp-29p::GFP, coel-12p::DsRed] IV; nas- } \\
\text { 38(knu568), snf-12(tm692) X. }\end{array}$ & This project & $\begin{array}{l}\text { HBR2190 (3B, 3H, } \\
\text { S3D) }\end{array}$ \\
\hline pmk-1(km25) IV; nas-38(knu568) X. & This project & $\begin{array}{l}\text { HBR2196 (3B, 3H, } \\
\text { S3D) }\end{array}$ \\
\hline bqSi506 [rgef-1p::FLP D5 + unc-119(+)] IV. & [72] & HBR2202 (S6F) \\
\hline $\operatorname{aptf-1(gk794)~II.~}$ & {$[22]$} & $\begin{array}{l}\text { HBR227 (1G-H, } \\
5 \mathrm{D}, 6 \mathrm{~A}, 7 \mathrm{~A}-\mathrm{B})\end{array}$ \\
\hline$n p r-12(t m 1498) I V$. & $\begin{array}{l}t m 1498 \text { provided } \\
\text { by Dong Yan }\end{array}$ & $\begin{array}{l}\text { HBR2301 (6B, } \\
\text { S6E) }\end{array}$ \\
\hline
\end{tabular}




\begin{tabular}{|c|c|c|}
\hline $\begin{array}{l}\text { npr-12(tm1498) IV; goeIs326[hsp-16.2p::nlp- } \\
\text { 29::SL2-mkate2-unc-54-3'UTR, unc-119(+)]. }\end{array}$ & This Project & HBR2302 (6B) \\
\hline$n l p-8(\operatorname{syb} 762) I V$. & This project & HBR2317 (S5A-B) \\
\hline nlp-8(syb762) IV; nas-38(ok3407) X. & This project & HBR2318 (s5A-B) \\
\hline ceh-14(ch3) X. & $\begin{array}{l}\text { Backcrossed from } \\
\text { CGC }\end{array}$ & HBR2364 (5D) \\
\hline $\begin{array}{l}\text { frIs7[nlp-29p::GFP, coel-12p::DsRed] IV; sta- } \\
\text { 2(ok1860)V. }\end{array}$ & This project & $\begin{array}{l}\text { HBR2375 (3F, } \\
\text { S3G) }\end{array}$ \\
\hline $\begin{array}{l}\text { pmk-1(km25), frIs7 [nlp-29p::GFP, coel- } \\
\text { 12p::DsRed] IV; nas-38(ok3407) X. }\end{array}$ & This project & $\begin{array}{l}\text { HBR2376 (3H, } \\
\text { S4E, S4G) }\end{array}$ \\
\hline $\begin{array}{l}\text { npr-12(tm1498) IV; goeEx738[nmr-1p::npr- } \\
\text { 12::SL2::mkate2-unc-54-3'UTR, unc-119(+)]]. }\end{array}$ & This project & HBR2426 (6C) \\
\hline $\begin{array}{l}\text { goeIs326 [phsp16.2::nlp-29::SL2-mkate2-unc-54- } \\
\text { 3'UTR, unc-119(+)]; goeEx738[nmr-1p::npr- } \\
\text { 12::SL2::mkate2-unc-54-3'UTR, unc-119(+)]. }\end{array}$ & This project & HBR2427 (6C) \\
\hline $\begin{array}{l}\text { npr-12(tm1498) IV; goeIs326 [phsp16.2::nlp- } \\
\text { 29::SL2-mkate2-unc-54-3'UTR, unc-119(+)]; } \\
\text { goeEx738[nmr-1p::npr-12::SL2::mkate2-unc-54- } \\
\text { 3'UTR, unc-119(+)]. }\end{array}$ & This project & HBR2428 (6C) \\
\hline $\begin{array}{l}\text { goeEx738[nmr-1p::npr-12::SL2::mkate2-unc-54- } \\
\text { 3'UTR, unc-119(+)]. }\end{array}$ & This project & HBR2444 (6C) \\
\hline $\begin{array}{l}\text { let-23(zh131[FRT::let- } \\
\text { 23::FRT::GFP::LoxP::FLAG::let-23] II; bqSi506 } \\
\text { [rgef-1p::FLP D5 + unc-119(+)] IV; sta-2(ok1860) } \\
\text { V. }\end{array}$ & This project & HBR2487 (5E) \\
\hline $\begin{array}{l}\text { aptf-1(gk794) II; nas-38 (ok3407) X; } \\
\text { goeIs118[aptf-1-5'utr::SL1-GCaMP3.35- } \\
\text { SL2::mKate2-aptf-1-3'utr,unc-119(+)]. }\end{array}$ & This project & HBR977 (1G-H) \\
\hline sta-2(ok1860) V. & [38] & $\begin{array}{l}\text { IG1241 (3B-C, 5E, } \\
\text { S6E) }\end{array}$ \\
\hline $\begin{array}{l}\text { frIs7[nlp-29p::GFP, coel-12p::DsRed] IV; snf- } \\
\text { 12(tm692) X. }\end{array}$ & {$[38]$} & $\begin{array}{l}\text { IG1242 (3B-C, 3G, } \\
\text { S4G) }\end{array}$ \\
\hline $\begin{array}{l}\text { frIs7(nlp-29p::GFP, coel-12p::DsRed) IV; dcar- } \\
\text { 1(tm2484) V. }\end{array}$ & [30] & $\begin{array}{l}\text { IG1424 (S3A-B, } \\
\text { S4C, S4G) }\end{array}$ \\
\hline $\begin{array}{l}\text { frSi11[pNP152(sta-2p::STA-2::mkate2), unc- } \\
119(+) \text { ttTi5605] II. }\end{array}$ & This project & IG1631 (2F-G) \\
\hline $\begin{array}{l}\text { frIs7[nlp-29p::GFP, coel-12p::DsRed] IV; dcar- } \\
\text { 1(tm2484) V; nas-38(ok3407) X. }\end{array}$ & This project & $\begin{array}{l}\text { IG1670 (3H, S3A- } \\
\text { B, S4C, S4G) }\end{array}$ \\
\hline $\begin{array}{l}\text { frIs7[nlp-29p::GFP, coel-12p::DsRed] IV; nas- } \\
\text { 38(ok3407), nipi-3(fr4) X. }\end{array}$ & This project & $\begin{array}{l}\text { IG1676 (3H, S3A- } \\
\text { B, S4D, S4G) }\end{array}$ \\
\hline $\begin{array}{l}\text { frIs7[nlp-29p::GFP, coel-12p::DsRed] IV; nas- } \\
\text { 38(ok3407), snf-12(tm692) X. }\end{array}$ & This project & $\begin{array}{l}\text { IG1803 (3C, 3G-H, } \\
\text { S3C, S4G) }\end{array}$ \\
\hline $\begin{array}{l}\text { frIs7[nlp-29p::GFP, col-12p::DsRed] IV; rde- } \\
\text { 1(ne300) V. }\end{array}$ & [53] & IG1847 \\
\hline
\end{tabular}




\begin{tabular}{|c|c|c|}
\hline $\begin{array}{l}\text { nas-38(ok3407) X; frIs7[nlp-29p::GFP, col- } \\
\text { 12p::DsRed] IV; rde-1(ne300) V. }\end{array}$ & This project & IG1991 (S4H) \\
\hline $\begin{array}{l}\text { nas-38(ok3407) X; frIs7[nlp-29p::GFP, col- } \\
\text { 12p::DsRed] IV; rde-1(ne300) V; frSi21[pSO21(col- } \\
\text { 62p::RDE-1_3'rde-1 ttTi5605] I. }\end{array}$ & This project & IG1992 (3I) \\
\hline $\begin{array}{l}\text { frIs7[nlp-29p::GFP, coel-12p::DsRed] IV; nipi- } \\
\text { 3(fr4) X. }\end{array}$ & [29] & $\begin{array}{l}\text { IG342 (S3A-B, } \\
\text { S4D, S4G) }\end{array}$ \\
\hline $\begin{array}{l}\text { pmk-1(km25), frIs7[nlp-29p::GFP, coel- } \\
12 p:: D s R e d] I V .\end{array}$ & {$[29]$} & IG460 \\
\hline $\begin{array}{l}\text { frIs7[nlp-29p::GFP, coel-12p::DsRed] IV; gpa- } \\
12(p k 322) X .\end{array}$ & [37] & $\begin{array}{l}\text { IG722 (3E, S3A-B, } \\
\text { S4G) }\end{array}$ \\
\hline$p m k-1(\mathrm{~km} 25) \mathrm{IV}$. & CGC & KU25 (3B-C) \\
\hline$d b l-1(n k 3) V$ & CGC & NU3 (3B-C) \\
\hline $\begin{array}{l}\text { nlp-8(syb762) I; nlp-32(syb431), cnc-6(syb393) } \\
\text { III, Y43C5A.3(syb761) IV; sybDf1, sybDf2, cnc- } \\
7(\text { syb558), cnc-10(syb937), nlp-25(syb579) V. }\end{array}$ & $\begin{array}{l}\text { SunyBiotech for } \\
\text { this project }\end{array}$ & $\begin{array}{l}\text { PHX1446 (4A-C, } \\
5 \mathrm{E}, 7 \mathrm{~A}-\mathrm{B})\end{array}$ \\
\hline $\begin{array}{l}\text { nlp-8(syb762) I; nlp-32(syb431), cnc-6(syb393) } \\
\text { III, Y43C5A.3(syb761) IV; sybDf1, sybDf2, cnc- } \\
\text { 7(syb558), cnc-10(syb937), nlp-25(syb579) V; } \\
\text { nas-38(ok3407) X. }\end{array}$ & $\begin{array}{l}\text { SunyBiotech for } \\
\text { this project }\end{array}$ & $\begin{array}{l}\text { PHX1521 (4A-B, } \\
\text { 4D) }\end{array}$ \\
\hline nas-38(syb293) X. & $\begin{array}{l}\text { SunyBiotech for } \\
\text { this project }\end{array}$ & PHX293 (S1A-B) \\
\hline \multicolumn{3}{|l|}{ Bacterial Strains } \\
\hline Escherichia coli & CGC & OP50 \\
\hline \multicolumn{3}{|l|}{ Deposited Data } \\
\hline Raw and analyzed data & This study & $\begin{array}{l}\underline{\text { https://doi.org/1 }} \\
\underline{0.5061 / \text { dryad.j3t }} \\
\underline{\text { x } 95 \mathrm{xbq}}\end{array}$ \\
\hline Original RNAseq data from nas-38 mutants & This study & $\begin{array}{l}\text { https://www.ncb } \\
\text { i.nlm.nih.gov/geo } \\
\text { Lquery/acc.cgi?ac } \\
\text { c=GSE146642 } \\
\text { (update when } \\
\text { released) }\end{array}$ \\
\hline Original RNAseq data from infected worms & {$[50]$} & $\begin{array}{l}\text { https://www.ncbi.nlm } \\
\text {.nih.gov/pmc/articles } \\
\text { /PMC3094335/bin/p } \\
\text { one.0019055.s011.xl } \\
\text { s }\end{array}$ \\
\hline Original RNAseq data from lethargus vs wake analysis & [51] & $\begin{array}{l}\underline{\text { https://doi.org/1 }} \\
\underline{0.1371 / \text { journal.p }} \\
\underline{\text { one.0113269.s00 }} \\
\underline{1}\end{array}$ \\
\hline \multicolumn{3}{|l|}{ Oligonucleotides } \\
\hline Primers for genotyping, see Table S3 & This study & $\mathrm{N} / \mathrm{A}$ \\
\hline
\end{tabular}




\begin{tabular}{|c|c|c|}
\hline nas-38p::d1mgfp::nas-38-3'-utr & This study & K185 \\
\hline flp-11p::egl-1::SL2-mkate2-flp-11-3'utr & This study & K281 \\
\hline $\begin{array}{l}\text { aptf-1-5'utr::SL1-GCaMP3.35-SL2::mKate2-aptf- } \\
\text { 1-3'utr }\end{array}$ & This study & K82 \\
\hline sta-2p::sta-2::mkate2 & This study & pNP152 \\
\hline hsp-16.2p::nlp-29::SL2-mkate2-unc-54-3'utr & This study & K271 \\
\hline hsp-16.2p::cnc-1::SL2-mkate2-unc-54-3'utr & This study & K305 \\
\hline hsp-16.2p::cnc-10::SL2-mkate2-unc-54-3'utr & This study & K304 \\
\hline hsp-16.2p::cnc-11::SL2-mkate2-unc-54-3'utr & This study & K284 \\
\hline hsp-16.2p::cnc-2::SL2-mkate2-unc-54-3'utr & This study & K282 \\
\hline hsp-16.2p::cnc-4::SL2-mkate2-unc-54-3'utr & This study & K294 \\
\hline hsp-16.2p::cnc-6::SL2-mkate2-unc-54-3'utr & This study & K283 \\
\hline hsp-16.2p::cnc-7::SL2-mkate2-unc-54-3'utr & This study & K295 \\
\hline hsp-16.2p::cnc-9::SL2-mkate2-unc-54-3'utr & This study & K296 \\
\hline hsp-16.2p::Y43C5A.3::SL2-mkate2-unc-54-3'utr & This study & K292 \\
\hline hsp-16.2p::nlp-8::SL2-mkate2-unc-54-3'utr & This study & K285 \\
\hline hsp-16.2p::nlp-25::SL2-mkate2-unc-54-3'utr & This study & K286 \\
\hline hsp-16.2p::nlp-27::SL2-mkate2-unc-54-3'utr & This study & K287 \\
\hline hsp-16.2p::nlp-30::SL2-mkate2-unc-54-3'utr & This study & K288 \\
\hline hsp-16.2p::nlp-31::SL2-mkate2-unc-54-3'utr & This study & K289 \\
\hline hsp-16.2p::nlp-32::SL2-mkate2-unc-54-3'utr & This study & K290 \\
\hline hsp-16.2p::nlp-34::SL2-mkate2-unc-54-3'utr & This study & K291 \\
\hline $\begin{array}{l}\text { flp-11p::SL1-GCaMP3.35-SL2::mKate2-unc-54- } \\
\text { 3'utr }\end{array}$ & This study & K216 \\
\hline nmr-1p::npr-12::SL2-mkate2-unc-54-3'utr & This study & K365 \\
\hline \multicolumn{3}{|l|}{ Software and Algorithms } \\
\hline NIS Elements Advanced Research 5.02 & Nikon Instruments & $\begin{array}{l}\text { https://www.microsc } \\
\text { ope.healthcare.nikon } \\
\text { com/en EU/product } \\
\text { s/software/nis- } \\
\text { elements/nis- } \\
\text { elements-advanced- } \\
\text { research }\end{array}$ \\
\hline MATLAB (version R2019a) & Mathworks & $\begin{array}{l}\text { https://www.mathworks.co } \\
\text { m// products/matlab.html }\end{array}$ \\
\hline OriginPro (version 2020) & OriginLab & $\begin{array}{l}\text { https://www.originlab } \\
\text {.com/index.aspx?go } \\
\text { =Products/Origin }\end{array}$ \\
\hline
\end{tabular}

\section{Lead contact and materials availability}

Requests for resources and reagents should be directed to the Lead Contact, Henrik Bringmann (henrik.bringmann@biologie.uni-marburg.de). Key C. elegans strains that were used in this study are available from the Caenorhabditis elegans Genetics Center. 
Additional C. elegans strains, plasmids, or other reagents are available from the Lead Contact upon reasonable request.

\section{Data and code availability}

Raw and processed data as well as MatLab scripts can be accessed at https://doi.org/10.5061/dryad.j3tx95xbq (update when released).

The nas-38 transcriptomes are deposited at GEO under the accession number GSE146642 (update when released).

\section{Experimental model and subject details}

C. elegans hermaphrodites were grown under standard conditions [67]. Worms were maintained at $20^{\circ} \mathrm{C}$ on nematode growth medium (NGM) plates seeded with E. coli OP50, unless otherwise mentioned. The C. elegans strains used in this project are listed in the Key Resource Table.

\section{Method details}

\section{Creation of transgenic animals}

By using the Three Fragment Gateway System (Invitrogen) [68], constructs were cloned into the pCG150 Vector that contains an unc-119(+) rescue sequence. To verify the correct sequence of the cloned constructs, plasmids were Sanger-sequenced [69]. Transgenes were expression-optimized for $C$. elegans [70]. We generated the transgenic strains by microparticle bombardment into unc-119(ed3) mutant worms and used a phenotypical rescue of the uncoordinated phenotype as a selection marker [71, 72]. The insertions that were obtained were backcrossed two times against N2 to remove the unc-119(ed3) background. The constructs created for this project are listed in the Key Resource Table.

frSill is a single copy insertion on chromosome II at the location of the Nemagenetag Mos1 insertion [73] ttTi5605 of pNP152 (col-62p::Lifeact::mKate2-c-nmy3 'utr). pNP152 was obtained by insertion of the sta-2 promoter and sta-2 gene fused to Lifeact::mKate2 
[74] into the MosSCI vector pCFJ151 [75] using Gibson Assembly (NEB Inc., MA) and confirmed by PCR or sequencing. It was injected into the EG6699 strain at $20 \mathrm{ng} / \mu \mathrm{l}$ together with pCFJ90 (myo-2p::mCherry) at $1.25 \mathrm{ng} / \mu 1, \mathrm{pCFJ} 104$ (myo-3p::mCherry) at 5 ng/ $\mu 1$, pMA122 (hsp16.41p::PEEL-1) at $10 \mathrm{ng} / \mu 1$, pCFJ601 (eft-3p::Mos1 transposase) at $20 \mathrm{ng} / \mu \mathrm{l}$ and pNP21 (unc-53pB::GFP [76] ) at $40 \mathrm{ng} / \mu \mathrm{l}$. A strain containing the insertion was obtained following standard selection and PCR confirmation [75]. The strain was then outcrossed with $\mathrm{N} 2$ males to remove the $u n c-119$ mutation.

\section{Crossing $C$. elegans strains}

C. elegans strains that carry multiple mutations or transgenes were created by conventional crossings and genotyped phenotypically or by a three-primer polymerase chain reaction (PCR) approach. The primer pairs used in this project are listed in Table S3.

For measuring heterozygous nas-38 mutants, homozygous hermaphrodites were mated with homozygous $n l p-29 p:: G F P$ males. The resulting F1 generation was then analyzed for movement quiescence and lethargus duration. Green fluorescent worms were heterozygous, non-fluorescent worms were homozygous for the nas-38 mutation.

\section{Creating mutants with the CRISPR/Cas9 system}

Strain generation with mutations in the endogenous locus via CRISPR/Cas9 was performed by Knudra Transgenics and SunyBiotech. In the nas-38(ok3407) transcriptome, 17 nlp and cnc genes were significantly upregulated. Out of these 17 genes, we deleted 16 genes in the multi $n l p$ and $c n c$ knockout. As four of the significantly upregulated $c n c$ genes and five of the $n l p$ genes are organized in gene cassettes, we decided to delete those two cassettes completely to facilitate the generation of the multi knockout strain. This resulted in the knockout of three additional cassette members $c n c-3, c n c-5$ and $n l p-28$ that were all found upregulated in the nas-38(ok3407) background without reaching statistical significance. As both cassettes and 4 additional AMPs, namely $n l p-25, c n c-7, c n c-9$ and $c n c-10$, are located on chromosome $\mathrm{V}$ and because the 5 deletions on this chromosome were already difficult to cross due to frequent recombination, we decided to forego the knockout of $c n c-9$. cnc-9 was also not found to be upregulated upon infection [50]. The final strain thus contained the 
significantly upregulated $c n c-1, c n c-2, c n c-4, c n c-6, c n c-7, c n c-10, c n c-11, n l p-8, n l p-25$, $n l p-27, n l p-29, n l p-30, n l p-31, n l p-32, n l p-34$ and Y43C5A.3 as well as the additional cassette members $c n c-3, c n c-5$ and $n l p-28$, which also were upregulated in the nas38(ok3407) transcriptome, yet did not reach statistical significance. The multi knockout strain was not backcrossed. To corroborate the findings of the multi knockout strain, an RNAi experiment was performed.

\section{Genetic screen for increased behavioral quiescence}

We aimed to screen one mutation for each gene for which a mutation was available at the Caenorhabditis Genetics Center. We obtained a mutant collection consisting of about 4500 strains with each strain harboring at least one known severe mutation such as a deletion or a mutation that was previously associated with a phenotype. Because each strain had a mutation in a different gene, the mutant set covered strong alleles for at least 4500 different genes. The screen was carried out on $6 \mathrm{~cm}$ NGM plates seeded with a lawn of OP50 bacteria that were placed on the plates as a suspension in a drop of $200 \mu \mathrm{l} \mathrm{LB}$ medium. The plates were inoculated with 2-3 adult worms and grown at $20^{\circ} \mathrm{C}$ until a population of about 200300 individuals containing all developmental stages including animals that were in lethargus was visible on the plate. Each plate was scored by two researchers using a stereomicroscope for the presence of an excessive fraction of behaviorally quiescent animals. Worms were scored as quiescent only if they lacked both feeding and motion. The researchers were blind to the genotype of the strain during the screening process and could only see the strain names. The sensitivity of the screen for the detection of increased sleeping mutants was not tested, as mutants with increased sleep during lethargus had not been established. RB2467 clearly stood out among the high quiescence strains. It contained the nas-38(ok3407) allele, which was studied after backcrossing with wild type N2 worms. The other screen positives were not systematically investigated. (Supplementary Table 1).

\section{Imaging}


All long-term behavioral and functional $\mathrm{Ca}^{2+}$-imaging experiments presented in this project were performed in agarose microchambers $[23,77]$. The microchambers were created from 3-5 \% hot melting agarose (Fisher-Scientific) dissolved in S-Basal or M9. The hot agarose was then cast into a polydimethylsiloxan (PDMS) mold to create micro-compartments in the agarose. After solidification of the agarose, the PDMS mold was removed and the chambers were filled with one worm (eggs or adults) each. If a chamber appeared to dry out, water or M9 was added to keep it moist.

Adult worms were filmed in $370 \mu \mathrm{m} \times 370 \mu \mathrm{m} \times 45 \mu \mathrm{m}$ (X length $\times$ Y length $\times \mathrm{Z}$ depth) microchambers. L1 larvae were imaged in $190 \mu \mathrm{m}$ x $190 \mu \mathrm{m}$ x $15 \mu \mathrm{m}$ microchambers. For continuous imaging, adults and L1s were imaged with a 10x or 20x objective. L1 lethargus in the differential interference contrast (DIC) burst mode (explained below) was imaged with a $40 x$ objective.

The microscope setup consisted of the following components: Either a Nikon TiE inverted microscope was used that was equipped with an automated XY stage (Prior, Nikon), an LED system (CoolLED), Andor iXon electron multiplying charge-coupled device (EMCCD) camera (512×512 pixels), kinetic trigger device, automated Prior XY stage, Andor iQ2 or iQ3 or NIS Elements Advanced Research software and a home-made sample holder with a heat lid. Or a Nikon Ti2 inverted microscope was used that was equipped with an LED system (Lumencor Sola II), a Photometrics Prime 95B sCMOS camera (1608x1608 pixels), NIS Elements Advanced Research software and a custom-made sample holder with a heating lid. For fluorescence imaging, the transistor-transistor logic (TTL) trigger "fire out" of the camera was used to trigger the LED illumination. This decreased illumination time, because the sample was only illuminated during image acquisition.

\section{DIC imaging}

L1 lethargus was measured in DIC burst or continuous mode. In burst mode, every 15 or 30 min an acquisition burst with either 20 or 40 frames with a frame rate of 2 frames/s was 
recorded. Up to 60 worms were filmed in parallel. The DIC images were used to determine lethargus onset and the lethargus length based on the continuous absence of pharyngeal pumping. For continuous imaging, a frame rate of 0.2 frames/s was used for imaging L1 lethargus. Typically, 3-8 individual fields were filmed in parallel and up to 4 worms could be filmed in one field using the Andor EMCCD Camera and a 20x objective. The larger camera chip of the Photometrics Prime 95B allowed imaging 16 worms in one field using the 10x objective. Lethargus onset and end were determined optically by cessation and restart of feeding behavior. For adult wounding or heat shock experiments, a frame rate of 0.1 frames/s was used and only 1 worm was imaged per field. Lethargus was identified as the continuous phase of pumping cessation prior to cuticle shedding and sleeping behavior was extracted by quantifying bouts of movement quiescence that lasted for at least $1 \mathrm{~min}$ $[21]$.

\section{Functional $\mathrm{Ca}^{2+}$-imaging}

Standard GFP filter sets were used, the exposure time was set to $10 \mathrm{~ms}$ and gain to 200 . $490 \mathrm{~nm}$ light intensity was around $2.00 \mathrm{~mW} / \mathrm{mm}^{2}$ using a 20x objective. The frame rate used was 0.1 frame/s.

\section{Fluorescent imaging experiments}

We used fluorescent imaging in combination with the DIC burst mode to correlate gene expression with L1 lethargus onset, identified by cessation of pumping. Every $30 \mathrm{~min}$, a DIC burst was recorded followed by a single fluorescent image. The nlp-29p::GFP transcriptional reporter was recorded with standard GFP filter sets in L1 larvae, the exposure time was set to $5 \mathrm{~ms}$ and gain was set to 30 . A single image was taken using $490 \mathrm{~nm}$ light with an intensity of $0.41 \mathrm{~mW} / \mathrm{mm}^{2}$ using a $40 \mathrm{x}$ objective. If necessary, we used a neutral-density filter (ND4) to reduce excitation light intensity. For analysis of signal intensity, we used a lower intensity threshold of 250 arbitrary intensity units. In the L4 larvae, nlp-29p::GFP was imaged at the Ti2 setup using a 20x objective and an additional $1.5 \mathrm{x}$ internal lens. The exposure time was set to $1 \mathrm{~ms}$ and the light intensity was set to $17.32 \mathrm{~mW} / \mathrm{mm}^{2}$. 
The nas-38p::dlGFP transcriptional reporter was recorded with standard GFP filter sets, the exposure time was set to $5 \mathrm{~ms}$ and gain to 200 . A z-stack was recorded every $15 \mathrm{~min}$ with a plane distance of $1 \mu \mathrm{m}$ covering an overall distance of $20 \mu \mathrm{m}$. The $490 \mathrm{~nm}$ light intensity was $2.44 \mathrm{~mW} / \mathrm{mm}^{2}$ using a 40x objective. After acquisition, the maximum projection of the z-stack was calculated using Andor software. For analysis, the lower threshold was set to 8000 intensity units.

The sta-2p::sta-2::mkate2 translational reporter was recorded using standard TexasRed filter sets in the L4 larvae using a spinning disc setup and a 100x objective. The exposure time was set to $100 \mathrm{~ms}$ and the gain was set to 300 .

\section{Image analysis}

\section{Analyzing functional $\mathrm{Ca}^{2+}$-images}

From functional $\mathrm{Ca}^{2+}$ sensor images, we extracted two parameters: 1) the worm's locomotion velocity based on the movement of the neuron center and 2) the neuronal activity. Both parameters were determined by a custom-made MatLab (MathWorks) routine, similar to the one previously described [23].

For RIS depolarizing, the RIS activity was the average of the 30 highest pixel intensities in an 11 pixel x 11 pixel area around the detected pixel with the highest intensity. These 30 pixels represent the RIS cell body very robustly, which was determined empirically.

\section{Analyzing STA-2::mKate2 localization in nuclei}

Fluorescent signals of the STA-2::mKate2 reporter in nuclei was identified using the inbuilt circle finding function imfindcircles in MatLab (MathWorks) with the nuclei radius range set from $11-30$ pixels and a sensitivity of 0.92 .

\section{Fluorescent reporter analyses}


Analysis of $n l p-29 p:: G F P$ expression in Figure 2E, 3I, and S4H was quantified with the COPAS Biosort (Union Biometrica; Holliston, MA) as described in [54]. The ratio between GFP intensity and size (time of flight; TOF) is represented in arbitrary units. For the nas38 RNAi experiments, the worms were age-matched manually before the analyses as the nas-38 RNAi suppressed the developmental delay induced by nas-38(ok3407).

\section{Sleep detection}

Quiescence bouts in all conditions and ages had to last for at least $1 \mathrm{~min}$ to be classified as sleep. Empirically determined cut-off parameters were used for sleep detection. All data were smoothed using a $1^{\text {st }}$ degree polynomial local regression model over 5 time points using the in-build smooth function in MatLab. Image subtraction data of L1 lethargus measurements were normalized to the median of the highest 50 values and had to be below 0.2 to be counted as sleep. Data of wounded adults were normalized to the median of the highest 20 values. Image subtraction values had to be below 0.2 and velocity data from RIS GCaMP tracking had to be below 0.1 to be classified as sleep. Image subtraction data of adults after heat shock-induced $n l p-29$ expression were normalized to the median of the highest 500 values and the threshold was set to 0.5 . As nas-38(ok3407) mutants recover more slowly from L1 lethargus, phases of decreased mobility can be detected in rare cases also after feeding behavior was resumed especially before, during or after the molting process. An example for such an anachronistic phase of movement quiescence can be seen in Figure 1B. These were not counted as sleep.

\section{L1 and lethargus duration}

The duration of the entire L1 stage and the lethargus period were measured in microchambers at $20-22{ }^{\circ} \mathrm{C}$. Together with the internal controls, the nas-38(ok3407) development was measured using a DIC burst protocol and the nas-38(tm2655) developmental time was determined using continuous imaging. The following time points were manually extracted: the onset of hatching, the onset and end of lethargus (defined by the cessation and resumption of pharyngeal pumping) and the shedding of the cuticle. From these time points the duration of the L1 wake stage was determined as the time between 
hatching and non-pumping onset and lethargus length was determined as the period before cuticle shedding during which animals did not feed.

\section{Heat shock}

To induce overexpression of AMPs, we generated transgenes that drive expression of the $c n c$ or $n l p$ gene from the $h s p-16.2$ promoter. Expression from this promoter is strongly increased at temperatures above $33^{\circ} \mathrm{C}$ [78]. For the screen of sleep induction by overexpression of the individual AMPs, worms were picked to small NGM plates with a diameter of $35 \mathrm{~mm}$ and a height of $10 \mathrm{~mm}$, filled with approximately $3.5 \mathrm{ml}$ of NGM and seeded with E. coli OP50 bacteria, and sleep behavior was quantified. The plates were sealed tightly using Parafilm (Pechiney Plastic Packaging). After 10 min of heat shock in a water bath at $37^{\circ} \mathrm{C}$ the plates were placed on crushed ice for $2 \mathrm{~min}$, to stop the heat shock. When removed from the ice, this time point was defined as $0 \mathrm{~h}$ and the number of behaviorally quiescence worms was scored manually for cessation of pumping and locomotion. Scoring was repeated in $30 \mathrm{~min}$ intervals for at least two hours as described $[19,40]$.

For testing for suppression of the $n l p-29$ OE-induced sleep with the NPR-12 receptor gene knockout, a home-made temperature control device with a Peltier element was used as described before [56]. In brief, up to 15 young adult worms were transferred into agarose chambers $(370 \mu \mathrm{m} \times 370 \mu \mathrm{m} \times 45 \mu \mathrm{m})$ without food. We sealed the microchambers with a coverslip, thereby distributing the worms into individual microchambers. The coverslip was then attached with sticky tape to a metal plate of the temperature control device that had an opening cut-out, and the device was mounted onto the microscope. For applying the heat shock, the heater was set to $38^{\circ} \mathrm{C}$, resulting in $37^{\circ} \mathrm{C}$ in the chamber for $15 \mathrm{~min}$, as measured by a thermoelement. 3 min before the heat shock, the heating lid was set to 39.5 ${ }^{\circ} \mathrm{C}$. Before and after the heat shock period, the heating lid was set to $25.5^{\circ} \mathrm{C}$ and the heater was turned off, resulting in room temperature of the sample inside the agarose chamber. During the experiment, each worm was imaged every $10 \mathrm{~s}$ and for at least $4 \mathrm{~h}$. For quantifying quiescence behavior, the first $30 \mathrm{~min}$ before the heat shock were used as 
baseline. The first 30min directly after the heat shock were used to determine stress induced sleep and the following $3.25 \mathrm{~h}$ were used to determine sleep induced by the overexpression.

\section{RNAi-by-feeding}

RNAi expressing plasmids used were based on the LH4440 feeding vector [79]. The plasmids were transformed into the HT115 E. coli strain and RNA expression was induced by $1 \mathrm{mM}$ isopropyl- $\beta$-d-thiogalactopyranoside (IPTG, Sigma-Aldrich). For the multi nlp/cnc RNAi, we used a slightly modified version of the established RNAi-by-feeding protocol [80]. E. coli were cultured overnight in LB medium (50 $\mu \mathrm{g} / \mathrm{ml}$ ampicillin, Roth) and then seeded to freshly made NMG plates containing 1mM of IPTG (Sigma-Aldrich) and $25 \mu \mathrm{g} / \mathrm{ml}$ carbenicillin (carbenicillin disodium salt, Biomol). They were left to dry for one day. Then, L4 larvae were transferred to the plates and were allowed to grow for at least $24 \mathrm{~h}$ until the adult stage. The eggs were then used for experiments and were transferred into microchambers for imaging. The bacteria used in the microchambers were the same dsRNA expressing HT115 as the ones on which the parents had been fed. For the nas-38 RNAi experiments, worms were synchronized through standard procedure and transferred onto RNAi plates at the L1 stage. The nas-38(ok3407); frIs 7 strain was compared to the RNAi-resistant strain (rde-1(-); nas-38(ok3407); frIs7) and to epidermisspecific RNAi susceptible strain (rde-1; frSi21(col-19p:rde-1); nas-38(ok3407); frIs7), [53].

\section{Transcriptome analysis}

For transcriptome analysis, we synchronized worms by picking adult worms to fresh plates, letting them lay eggs for $3 \mathrm{~h}$ and then removed the adults. We aimed to include worms in all stages of the non-pumping period into the analysis. Therefore, for all offspring, we picked 150 individuals per sample and selected individuals that were in L4 lethargus for both wild type and mutants. We prepared three biological replicates. The larvae were collected in TRIzol (Invitrogen) and stored at $-80^{\circ} \mathrm{C}$ [81]. IMGM Laboratories $\mathrm{GmbH}$ 
performed RNA isolation, RNA sequencing and computation of differential gene expression (DGE) analysis. At IMGM, RNA was isolated using the RNeasy lipid tissue kit (Qiagen) with mechanical homogenization by steel beads and on-column DNase digestion. The RNA concentration and purity were measured using the NanoDrop ND-1000 spectral photometer (Peqlab). The purity was measured by the A260/A280 ratio and only RNA samples with A260/A280 ratios $\geq 1.6$ were used for RNA sequencing. RNA degradation was measured on a 2100 Bioanalyzer (Agilent Technologies) using RNA 6000 Pico LabChip kits (Agilent Technologies). The RNA was separated according to fragment size and the RNA integrity number (RIN) calculated from the electrophoretic profile [82]. Only samples with a RIN $>7.5$ were used for sequencing. Library preparation was performed with the TruSeq ${ }^{\circledR}$ Stranded mRNA HT technology. 300 ng RNA was fragmented by divalent cations. Using reverse transcription, single cDNA strands were created. For the second cDNA strand, dUTP was incorporated instead of dTTP, to avoid amplification by the DNA polymerase in the subsequent PCR. This guaranteed strandedness. 3'-ends were adenylated and ligated with sequencing primers, flow cell-binding sites, and indices for sequencing of pooled libraries. Adapter-ligated fragments were amplified by PCR. After the PCR and at the end of the library preparation, all samples were quality controlled using DNA 1000 LabChip kits on the 2100 Bioanalyzer. 5.4 ng DNA of each sample was used for final library pooling, subsequently diluted to $2 \mathrm{nM}$ and denatured with $\mathrm{NaOH}$.

Sequencing of the library was performed at a final concentration of $1.8 \mathrm{pM}$ and with a $1 \%$ PhiX v3 control library spike-in (Illumina) on the NextSeq500 sequencing system (Illumina). For cluster generation and sequencing of all samples, 75 cycles of paired-end runs were performed with the final library. Sequencing was controlled by the NextSeq Control Software. Before sequencing, clusters were generated by bridge amplification. The sequencing principle based on the sequencing by synthesis (SBS) approach and twochannel signal detection. By different fluorescent-labeled terminator dNTPs, the nucleotides were determined.

The RNA-Seq analysis was performed with the CLC genomics workbench "RNA-Seq analysis" tool. It maps the next-generation sequencing reads against the current $C$. elegans 
genome NC_001328 from NCBI. The following mapping parameters were applied: mismatch cost: 2 , insertion/deletion cost: 3 , length fraction: 0.8 , similarity fraction: 0.8 , local alignment, maximum number of hits per read: 5 .

The expression values were normalized to reads per kilobase of exon model per million mapped reads (RPKM) [83]. The differentially expressed transcripts were calculated. The comparisons were based on the "total exon reads" expression values to allow subsequent statistical analysis by "empirical analysis of DGE". To analyze significant expression, the exact test for two-group comparisons was used [84]. The dispersion of the data was chosen to be tag wise and the total count filter cutoff threshold was set to 100 . To control the false discovery rate (FDR), FDR corrected p-values were calculated and stringent filtering was used. A feature was classified "upregulated" if its FDR-corrected p-value was $\leq 0.05$ and fold change was $\geq 2$. Analogously, a gene was classified "downregulated" if its FDRcorrected p-value was $\leq 0.05$ and fold change was $\leq-2$. By using stringent filtering, all features outside of these thresholds were filtered out of the data. All differentially expressed genes are listed in Supplementary Table 2.

To compare transcriptional changes of $n l p s$ and $c n c s$ with other transcriptomes, we extracted expression values of all $n l p$ and $c n c$ genes along with Y43C5A.3. For genes for which there was more than one isoform, the average was calculated. Then, we determined the log fold change as follows: the $\log _{2}$ of the mean of the expression values of all three samples per genotype was calculated and the result of the wild-type samples subtracted from the results of the nas-38(ok3407) samples. The AMP expression fold change was then compared to the infection transcriptome deriving from RNAseq $12 \mathrm{~h}$ after infection [50] and to the fold change between L3 wake and L4 lethargus transcriptome [51].

Tissue enrichment analysis on all genes found upregulated in the nas-38(ok3407) transcriptome was performed with the Gene Set Enrichment Analysis tool available from wormbase (Version WS274) using a q value threshold of 0.1 . 
GO Term analysis was performed using g:profiler. We analyzed the genes found upregulated in the nas-38(ok3407) background with default settings. Term size was set between 10 and 1000 to get rid of generic terms.

The heatmap in Figure 2A was designed with RPKM values using heatmapper.ca.

\section{Epidermal wounding}

For laser-induced wounding, we prepared agarose microchambers with young adults. This microchamber was set onto our microscope set-up that was additionally equipped with a $355 \mathrm{~nm}$ laser (Rapp Opto, DPSL-355/14, direct coupling). This laser set-up was typically used for laser ablation of cells [85]. The 100x SFluor objective was used and a laser pulse was delivered to the tail or the lateral posterior body. Before laser irradiation, the focal plane was adjusted to $7 \mu \mathrm{m}$ from the glass surface into the microchamber. The number of laser pulses varied between 1 and 5 and the laser power between $5 \%$ and $15 \%$, depending on the response behavior. After wounding, the behavior and the neuronal activity were measured. Worms that were strongly harmed and released internal contents were excluded.

For needle-based injury $[28,86]$, needles were pulled from glass capillaries (GC100F-10, $1 \mathrm{~mm}$ outer diameter, $0.58 \mathrm{~mm}$ inner diameter, Harvard Apparatus) using the Flaming/Brown micropipette puller (Model P-97, Shutter Instruments) with following configuration: Heat: 567, Pull: 110, Vel: 240, Del: 220. Needles were pulled so that they had a stiff pointed end. We wounded worms on the plate without prior immobilization. For needle wounding, only young adults were selected. Under the dissection microscope the worms were pricked at the tail or the lateral posterior body. Worms that lost internal content after wounding were excluded. This occurred in approximately $10 \%$ of the cases and did not depend on the genotype but rather on the position and pressure applied upon wounding the worm. 
In the presence of food, wild-type worms showed a highly variable behavioral response to wounding ranging from no sleep to $80 \%$ sleep with a median of $14.0 \%$ (Figure S6C). Moreover, worms that were placed in microchambers in the presence of OP50 bacteria often looked sick after a few hours. We hence measured behavioral quiescence in microchambers without food. Worms were grown on OP50 bacteria, wounded, and then placed in $370 \mu \mathrm{m} \times 370 \mu \mathrm{m} \times 45 \mu \mathrm{m}$ agarose microfluidic compartments without food and imaged for $6 \mathrm{~h}$ directly following the wounding process. Under these conditions, average sleep time was slightly decreased and less variant (Figure 5D).

\section{Survival assay}

Young adult worms were wounded with a needle and then placed on NGM plates seeded with OP50 bacteria so that each plate contained no more than ten worms. After 24h and $48 \mathrm{~h}$ worms were touched with an eyelash and scored as dead if they did not respond to the touch and did not feed. Worms were censored when they dried out at the plastic wall of the plate or could not be found.

\section{Quantification and Statistical Analysis}

Statistical tests used were the two-sample t-test with Welch-correction for suspected unequal variance, the Fishers exact test and the paired Wilcoxon rank test. * denotes $\mathrm{p} \leq$ 0.05 , ** denotes $\mathrm{p} \leq 0.01, * * *$ denotes $\mathrm{p} \leq 0.001$. All tests were performed with MatLab (MathWorks) or OriginPro software. All p-values are FDR-corrected using the BenjaminiHochberg-correction. The specific tests used are described in the respective figure captions. The boxplots show the $25 \%-75 \%$ percentile, the whiskers indicate the $10 \%-90 \%$ range. The grey line is the median. Fold changes in movement quiescence, lethargus or nlp-29p::GFP fluorescence measurements were calculated based on mean values. Larvae that did not develop properly or adult worms that lost internal content after wounding were excluded from all analysis. All plots were designed using OriginPro and Adobe Illustrator software. 


\section{References}

1. Majde, J.A., and Krueger, J.M. (2005). Links between the innate immune system and sleep. The Journal of allergy and clinical immunology 116, 1188-1198.

2. Zielinski, M.R., and Krueger, J.M. (2011). Sleep and innate immunity. Front Biosci (Schol Ed) 3, 632-642.

3. Toth, L.A., Tolley, E.A., and Krueger, J.M. (1993). Sleep as a prognostic indicator during infectious disease in rabbits. Proc Soc Exp Biol Med 203, 179192.

4. Bryant, P.A., Trinder, J., and Curtis, N. (2004). Sick and tired: Does sleep have a vital role in the immune system? Nature reviews. Immunology 4, 457-467.

5. Besedovsky, L., Lange, T., and Haack, M. (2019). The Sleep-Immune Crosstalk in Health and Disease. Physiol Rev 99, 1325-1380.

6. Landis, C.A., and Whitney, J.D. (1997). Effects of 72 hours sleep deprivation on wound healing in the rat. Research in nursing \& health 20, 259-267.

7. Mostaghimi, L., Obermeyer, W.H., Ballamudi, B., Martinez-Gonzalez, D., and Benca, R.M. (2005). Effects of sleep deprivation on wound healing. Journal of sleep research 14, 213-219.

8. Egydio, F., Tomimori, J., Tufik, S., and Andersen, M.L. (2011). Does sleep deprivation and morphine influence wound healing? Medical hypotheses 77, 353355.

9. Rechtschaffen, A., and Bergmann, B.M. (1995). Sleep deprivation in the rat by the disk-over-water method. Behavioural brain research 69, 55-63.

10. Saper, C.B., Fuller, P.M., Pedersen, N.P., Lu, J., and Scammell, T.E. (2010). Sleep state switching. Neuron 68, 1023-1042.

11. Weber, F., and Dan, Y. (2016). Circuit-based interrogation of sleep control. Nature 538, 51-59.

12. Bringmann, H. (2018). Sleep-Active Neurons: Conserved Motors of Sleep. Genetics 208, 1279-1289.

13. Krueger, J.M., Frank, M.G., Wisor, J.P., and Roy, S. (2016). Sleep function: Toward elucidating an enigma. Sleep medicine reviews 28, 46-54.

14. Ehlen, J.C., Brager, A.J., Baggs, J., Pinckney, L., Gray, C.L., DeBruyne, J.P., Esser, K.A., Takahashi, J.S., and Paul, K.N. (2017). Bmall function in skeletal muscle regulates sleep. eLife 6 .

15. Hill, A.J., Mansfield, R., Lopez, J.M., Raizen, D.M., and Van Buskirk, C. (2014). Cellular stress induces a protective sleep-like state in C. elegans. Curr Biol 24, 2399-2405.

16. Van Buskirk, C., and Sternberg, P.W. (2007). Epidermal growth factor signaling induces behavioral quiescence in Caenorhabditis elegans. Nat Neurosci 10, 13001307.

17. Boman, H.G. (2003). Antibacterial peptides: basic facts and emerging concepts. J Intern Med 254, 197-215.

18. Toda, H., Williams, J.A., Gulledge, M., and Sehgal, A. (2019). A sleep-inducing gene, nemuri, links sleep and immune function in Drosophila. Science 363, 509515. 
19. Raizen, D.M., Zimmerman, J.E., Maycock, M.H., Ta, U.D., You, Y.J., Sundaram, M.V., and Pack, A.I. (2008). Lethargus is a Caenorhabditis elegans sleep-like state. Nature 451, 569-572.

20. Cassada, R.C., and Russell, R.L. (1975). The dauerlarva, a post-embryonic developmental variant of the nematode Caenorhabditis elegans. Dev Biol 46, 326342.

21. Iwanir, S., Tramm, N., Nagy, S., Wright, C., Ish, D., and Biron, D. (2013). The microarchitecture of $\mathrm{C}$. elegans behavior during lethargus: homeostatic bout dynamics, a typical body posture, and regulation by a central neuron. sleep 36 , 385-395.

22. Turek, M., Lewandrowski, I., and Bringmann, H. (2013). An AP2 transcription factor is required for a sleep-active neuron to induce sleep-like quiescence in $\mathrm{C}$. elegans. Curr Biol 23, 2215-2223.

23. Urmersbach, B., Besseling, J., Spies, J.P., and Bringmann, H. (2016). Automated analysis of sleep control via a single neuron active at sleep onset in C. elegans. Genesis 54, 212-219.

24. Nichols, A.L.A., Eichler, T., Latham, R., and Zimmer, M. (2017). A global brain state underlies C. elegans sleep behavior. Science 356.

25. Kim, D.H., and Ewbank, J.J. (2018). Signaling in the innate immune response. WormBook 2018, 1-35.

26. Ermolaeva, M.A., and Schumacher, B. (2014). Insights from the worm: the C. elegans model for innate immunity. Seminars in immunology 26, 303-309.

27. Cohen, L.B., and Troemel, E.R. (2015). Microbial pathogenesis and host defense in the nematode C. elegans. Current opinion in microbiology 23, 94-101.

28. Pujol, N., Cypowyj, S., Ziegler, K., Millet, A., Astrain, A., Goncharov, A., Jin, Y., Chisholm, A.D., and Ewbank, J.J. (2008). Distinct innate immune responses to infection and wounding in the C. elegans epidermis. Curr Biol 18, 481-489.

29. Zugasti, O., Bose, N., Squiban, B., Belougne, J., Kurz, C.L., Schroeder, F.C., Pujol, N., and Ewbank, J.J. (2014). Activation of a G protein-coupled receptor by its endogenous ligand triggers the innate immune response of Caenorhabditis elegans. Nature immunology 15, 833-838.

30. Taffoni, C., Omi, S., Huber, C., Mailfert, S., Fallet, M., Rupprecht, J.F., Ewbank, J.J., and Pujol, N. (2020). Microtubule plus-end dynamics link wound repair to the innate immune response. eLife 9.

31. Belougne, J., Ozerov, I., Caillard, C., Bedu, F., and Ewbank, J.J. (2020). Fabrication of sharp silicon arrays to wound Caenorhabditis elegans. Sci Rep 10, 3581.

32. Ewbank, J.J., and Pujol, N. (2016). Local and long-range activation of innate immunity by infection and damage in C. elegans. Current opinion in immunology 38, 1-7.

33. Kim, D.H., Feinbaum, R., Alloing, G., Emerson, F.E., Garsin, D.A., Inoue, H., Tanaka-Hino, M., Hisamoto, N., Matsumoto, K., Tan, M.W., et al. (2002). A conserved p38 MAP kinase pathway in Caenorhabditis elegans innate immunity. Science 297, 623-626. 
34. Nicholas, H.R., and Hodgkin, J. (2004). Responses to infection and possible recognition strategies in the innate immune system of Caenorhabditis elegans. Molecular immunology 41, 479-493.

35. Ziegler, K., Kurz, C.L., Cypowyj, S., Couillault, C., Pophillat, M., Pujol, N., and Ewbank, J.J. (2009). Antifungal innate immunity in C. elegans: PKCdelta links G protein signaling and a conserved p38 MAPK cascade. Cell host \& microbe 5 , 341-352.

36. Dierking, K., Polanowska, J., Omi, S., Engelmann, I., Gut, M., Lembo, F., Ewbank, J.J., and Pujol, N. (2011). Unusual regulation of a STAT protein by an SLC6 family transporter in C. elegans epidermal innate immunity. Cell host \& microbe 9, 425-435.

37. Gumienny, T.L., and Savage-Dunn, C. (2013). TGF-beta signaling in C. elegans. WormBook, 1-34.

38. Zugasti, O., and Ewbank, J.J. (2009). Neuroimmune regulation of antimicrobial peptide expression by a noncanonical TGF-beta signaling pathway in Caenorhabditis elegans epidermis. Nature immunology 10, 249-256.

39. Park, J.O., Pan, J., Mohrlen, F., Schupp, M.O., Johnsen, R., Baillie, D.L., Zapf, R., Moerman, D.G., and Hutter, H. (2010). Characterization of the astacin family of metalloproteases in C. elegans. BMC developmental biology 10, 14.

40. Turek, M., Besseling, J., Spies, J.P., Konig, S., and Bringmann, H. (2016). Sleepactive neuron specification and sleep induction require FLP-11 neuropeptides to systemically induce sleep. eLife 5 .

41. Wu, Y., Masurat, F., Preis, J., and Bringmann, H. (2018). Sleep Counteracts Aging Phenotypes to Survive Starvation-Induced Developmental Arrest in C. elegans. Curr Biol 28, 3610-3624 e3618.

42. Corish, P., and Tyler-Smith, C. (1999). Attenuation of green fluorescent protein half-life in mammalian cells. Protein Eng 12, 1035-1040.

43. Hunt-Newbury, R., Viveiros, R., Johnsen, R., Mah, A., Anastas, D., Fang, L., Halfnight, E., Lee, D., Lin, J., Lorch, A., et al. (2007). High-throughput in vivo analysis of gene expression in Caenorhabditis elegans. PLoS biology 5, e237.

44. Hendriks, G.J., Gaidatzis, D., Aeschimann, F., and Grosshans, H. (2014). Extensive oscillatory gene expression during C. elegans larval development. Molecular cell 53, 380-392.

45. Pujol, N., Davis, P.A., and Ewbank, J.J. (2012). The Origin and Function of AntiFungal Peptides in C. elegans: Open Questions. Front Immunol 3, 237.

46. Dodd, W., Tang, L., Lone, J.C., Wimberly, K., Wu, C.W., Consalvo, C., Wright, J.E., Pujol, N., and Choe, K.P. (2018). A Damage Sensor Associated with the Cuticle Coordinates Three Core Environmental Stress Responses in Caenorhabditis elegans. Genetics 208, 1467-1482.

47. Kim, D., Grun, D., and van Oudenaarden, A. (2013). Dampening of expression oscillations by synchronous regulation of a microRNA and its target. Nature genetics 45, 1337-1344.

48. George-Raizen, J.B., Shockley, K.R., Trojanowski, N.F., Lamb, A.L., and Raizen, D.M. (2014). Dynamically-expressed prion-like proteins form a cuticle in the pharynx of Caenorhabditis elegans. Biol Open 3, 1139-1149. 
49. Miao, R., Li, M., Zhang, Q., Yang, C., and Wang, X. (2020). An ECM-to-Nucleus Signaling Pathway Activates Lysosomes for C. elegans Larval Development. Developmental cell 52, 21-37 e25.

50. Engelmann, I., Griffon, A., Tichit, L., Montanana-Sanchis, F., Wang, G., Reinke, V., Waterston, R.H., Hillier, L.W., and Ewbank, J.J. (2011). A comprehensive analysis of gene expression changes provoked by bacterial and fungal infection in C. elegans. PLoS One 6, e19055.

51. Turek, M., and Bringmann, H. (2014). Gene expression changes of Caenorhabditis elegans larvae during molting and sleep-like lethargus. PLoS One 9, e113269.

52. Couillault, C., Pujol, N., Reboul, J., Sabatier, L., Guichou, J.F., Kohara, Y., and Ewbank, J.J. (2004). TLR-independent control of innate immunity in Caenorhabditis elegans by the TIR domain adaptor protein TIR-1, an ortholog of human SARM. Nature immunology 5, 488-494.

53. Watts, J.S., Harrison, H.F., Omi, S., Guenthers, Q., Dalelio, J., Pujol, N., and Watts, J.L. (2020). New Strains for Tissue-Specific RNAi Studies in Caenorhabditis elegans. G3 (Bethesda).

54. Pujol, N., Zugasti, O., Wong, D., Couillault, C., Kurz, C.L., Schulenburg, H., and Ewbank, J.J. (2008). Anti-fungal innate immunity in C. elegans is enhanced by evolutionary diversification of antimicrobial peptides. PLoS pathogens 4 , e1000105.

55. Goetting, D.L., Mansfield, R., Soto, R., and Van Buskirk, C. (2020). Cellular damage, including wounding, drives C. elegans stress-induced sleep. Journal of Neurogenetics.

56. Konietzka, J., Fritz, M., Spiri, S., McWhirter, R., Leha, A., Palumbos, S., Costa, W.S., Oranth, A., Gottschalk, A., Miller, D.M., 3rd, et al. (2020). Epidermal Growth Factor Signaling Promotes Sleep through a Combined Series and Parallel Neural Circuit. Curr Biol 30, 1-16 e13.

57. E, L., Zhou, T., Koh, S., Chuang, M., Sharma, R., Pujol, N., Chisholm, A.D., Eroglu, C., Matsunami, H., and Yan, D. (2018). An Antimicrobial Peptide and Its Neuronal Receptor Regulate Dendrite Degeneration in Aging and Infection. Neuron 97, 125-138 e125.

58. Taylor, S.R., Santpere, G., Reilly, M., Glenwinkel, L., Poff, A., McWhirter, R., Xu, C., Weinreb, A., Basavaraju, M., Cook, S.J., et al. (2019). Expression profiling of the mature $<\mathrm{em}>\mathrm{C}$. elegans $</ \mathrm{em}>$ nervous system by single-cell RNA-Sequencing. bioRxiv, 737577.

59. Maluck, E., Busack, I., Besseling, J., Masurat, F., Turek, M., Busch, K.E., and Bringmann, H. (2020). A wake-active locomotion circuit depolarizes a sleepactive neuron to switch on sleep. PLoS biology 18, e3000361.

60. Kessler, E., Takahara, K., Biniaminov, L., Brusel, M., and Greenspan, D.S. (1996). Bone morphogenetic protein-1: the type I procollagen C-proteinase. Science 271, 360-362.

61. Hishida, R., Ishihara, T., Kondo, K., and Katsura, I. (1996). hch-1, a gene required for normal hatching and normal migration of a neuroblast in $\mathrm{C}$. elegans, encodes a protein related to TOLLOID and BMP-1. EMBO J 15, 4111-4122. 
62. Novelli, J., Ahmed, S., and Hodgkin, J. (2004). Gene interactions in Caenorhabditis elegans define DPY-31 as a candidate procollagen C-proteinase and SQT-3/ROL-4 as its predicted major target. Genetics 168, 1259-1273.

63. Davis, M.W., Birnie, A.J., Chan, A.C., Page, A.P., and Jorgensen, E.M. (2004). A conserved metalloprotease mediates ecdysis in Caenorhabditis elegans. Development 131, 6001-6008.

64. Suzuki, M., Sagoh, N., Iwasaki, H., Inoue, H., and Takahashi, K. (2004). Metalloproteases with EGF, CUB, and thrombospondin-1 domains function in molting of Caenorhabditis elegans. Biological chemistry 385, 565-568.

65. Zhang, Y., Li, W., Li, L., Li, Y., Fu, R., Zhu, Y., Li, J., Zhou, Y., Xiong, S., and Zhang, H. (2015). Structural damage in the C. elegans epidermis causes release of STA-2 and induction of an innate immune response. Immunity 42, 309-320.

66. Rohleder, N., Aringer, M., and Boentert, M. (2012). Role of interleukin-6 in stress, sleep, and fatigue. Annals of the New York Academy of Sciences 1261, 88-96.

67. Brenner, S. (1974). The genetics of Caenorhabditis elegans. Genetics 77, 71-94.

68. Merritt, C., and Seydoux, G. (2010). Transgenic solutions for the germline. WormBook, 1-21.

69. Sanger, F., and Coulson, A.R. (1975). A rapid method for determining sequences in DNA by primed synthesis with DNA polymerase. Journal of molecular biology 94, 441-448.

70. Redemann, S., Schloissnig, S., Ernst, S., Pozniakowsky, A., Ayloo, S., Hyman, A.A., and Bringmann, H. (2011). Codon adaptation-based control of protein expression in C. elegans. Nat Methods 8, 250-252.

71. Wilm, T., Demel, P., Koop, H.U., Schnabel, H., and Schnabel, R. (1999). Ballistic transformation of Caenorhabditis elegans. Gene 229, 31-35.

72. Praitis, V., Casey, E., Collar, D., and Austin, J. (2001). Creation of low-copy integrated transgenic lines in Caenorhabditis elegans. Genetics 157, 1217-1226.

73. Vallin, E., Gallagher, J., Granger, L., Martin, E., Belougne, J., Maurizio, J., Duverger, Y., Scaglione, S., Borrel, C., Cortier, E., et al. (2012). A genome-wide collection of Mos 1 transposon insertion mutants for the C. elegans research community. PLoS One 7, e30482.

74. Reymann, A.C., Staniscia, F., Erzberger, A., Salbreux, G., and Grill, S.W. (2016). Cortical flow aligns actin filaments to form a furrow. eLife 5 .

75. Frokjaer-Jensen, C., Davis, M.W., Hopkins, C.E., Newman, B.J., Thummel, J.M., Olesen, S.P., Grunnet, M., and Jorgensen, E.M. (2008). Single-copy insertion of transgenes in Caenorhabditis elegans. Nature genetics 40, 1375-1383.

76. Stringham, E., Pujol, N., Vandekerckhove, J., and Bogaert, T. (2002). unc-53 controls longitudinal migration in C. elegans. Development 129, 3367-3379.

77. Bringmann, H. (2011). Agarose hydrogel microcompartments for imaging sleepand wake-like behavior and nervous system development in Caenorhabditis elegans larvae. J Neurosci Methods 201, 78-88.

78. Stringham, E., Dixon, D., Jones, D., and Candido, E. (1992). Temporal and spatial expression patterns of the small heat shock (hsp16) genes in transgenic Caenorhabditis elegans. Molecular biology of the cell 3, 221-233. 
79. Timmons, L., and Fire, A. (2001). Ingestion of bacterially expressed dsRNAs can produce specific and potent genetic interference in Caenorhabditis elegans. Gene 263, 103-112.

80. Kamath, R.S., and Ahringer, J. (2003). Genome-wide RNAi screening in Caenorhabditis elegans. Methods 30, 313-321.

81. Simms, D., Cizdziel, P.E., and Chomczynski, P. (1993). TRIzol: A new reagent for optimal single-step isolation of RNA. Focus 15, 532-535.

82. Schroeder, A., Mueller, O., Stocker, S., Salowsky, R., Leiber, M., Gassmann, M., Lightfoot, S., Menzel, W., Granzow, M., and Ragg, T. (2006). The RIN: an RNA integrity number for assigning integrity values to RNA measurements. BMC molecular biology 7,3 .

83. Mortazavi, A., Williams, B.A., McCue, K., Schaeffer, L., and Wold, B. (2008). Mapping and quantifying mammalian transcriptomes by RNA-Seq. Nature methods 5, 621 .

84. Robinson, M.D., and Smyth, G.K. (2007). Small-sample estimation of negative binomial dispersion, with applications to SAGE data. Biostatistics 9, 321-332.

85. Fang-Yen, C., Gabel, C.V., Samuel, A.D., Bargmann, C.I., and Avery, L. (2012). Laser microsurgery in Caenorhabditis elegans. In Methods in cell biology, Volume 107. (Elsevier), pp. 177-206.

86. Xu, S., and Chisholm, A.D. (2014). Methods for skin wounding and assays for wound responses in C. elegans. Journal of visualized experiments: JoVE. 